\title{
Zur Wissenschaftsgeschichte der aDNA-Forschung
}

\author{
Elsbeth Bösl
}

aDNA Research From a Historical Perspective

aDNA studies are a cooperative field of research with a broad range of applications including evolutionary biology, genetics, anthropology and archaeology. Scientists are using ancient molecules as source material for historical questions. Colleagues from the humanities are observing this with both interest and concern because aDNA research is affecting academic identities and both concepts of history and historiography. aDNA research developed in a way that can be described as a Hype Cycle (Chackie Fenn). Technological triggers such as Sanger Sequencing and the Polymerase Chain Reaction kicked off a multitude of experiments with ancient DNA during the 1980s and 1990s. Geneticists, microbiologists, anthropologists and many more euphorically joined a "molecule hunt". aDNA was promoted as a time machine. Media attention was enormous. As experiments and implementations began to fail and contamination was discovered to be a tremendous problem, media interest waned and many labs lost their interest. Some turned their disillusionment into systematic research into methodology and painstakingly established lab routines. The authenticity problem was first addressed by control oriented measures but later approached from a more cognitive theoretical perspective as the pitfalls and limits of aDNA became clearer. By the end of the 2000s the field reached its current plateau of productivity. Cross-disciplinary debates, conflicts and collaborations are increasing critical reflection among all participants. Historians should consider joining the field in a kind of critical friendship to both make the most of its possibilities and give an input from a constructivist perspective.

Keywords: aDNA, Archaeology, Genetics, Interdisciplinary research

Die aDNA-Forschung hat die Geschichtswissenschaft erreicht. Das Anliegen dieses Beitrags ist es, Wissen über die historische Gewordenheit des epistemischen Objekts alte DNA und des überfachlichen Forschungsfeldes, das sich mit inr befasst, in die aktuelle Diskussion über den Stellenwert molekulargenetischer Quellen und Verfahren zur Bearbeitung historischer Fragestellungen einzubringen. Über den Bezug zum gemeinsamen Wissensgegenstand (alte) DNA traten ForscherInnen und Forscher aus verschiedenen Fächern und Disziplinen der Natur-, Kultur- und Geisteswissenschaften miteinander in Kontakt. Als Zeichen der Molekularisierung der Wissenschaften und der Gesellschaft kann man ansehen, dass diese Fächer sich eine molekulare Erkenntnisebene geschaffen, DNA zur Quelle für historische Fragestellungen definiert und damit für das Geschichtsbewusstsein relevant gemacht haben. Die Entwicklung dieses Forschungsfeldes seit den 1980er Jahren lässt sich mit dem Modell des Hype Cycle (Chackie Fenn) beschreiben. Auf dem Weg zu seinem momentanen Produktivitätsniveau erwiesen sich Kontaminationen und Authentifizierungsschwierigkeiten als die zentrale technische und methodische Herausforderung. Die Fragen, ob genetische und soziokulturelle Daten und Konzepte, DNAQuellen, Sachgut und Schriftquellen miteinander in Bezug gesetzt werden können und dürfen, und wem die Interpretationshoheit zukommen soll, gerieten hingegen zum wichtigsten Thema der überfachlichen Debatten. 


\section{Zum aktuellen Anlass}

Die Gründung des Max-Planck-Instituts für Menschheitsgeschichte (MPI$\mathrm{SHH}$ ) in Jena 2014 hat in der Geschichtswissenschaft für großes Interesse, aber auch für Irritationen gesorgt (Feuchter 2014). Zutage traten diese zum Beispiel auf dem Podium „Geschichte als Naturwissenschaft? Perspektiven biologischer Forschung in der Geschichtswissenschaft", zu dem im Januar 2016 die Historiker Jens Ivo Engels und Gerrit Schenk an die TU Darmstadt eingeladen hatten, um dort mit KollegInnen unter anderem über diese Fragen zu diskutieren: Wie betreiben GenetikerInnen oder BiochemikerInnen Geschichtsforschung? Was meinen sie, wenn sie von DNAMolekülen als Quellen, Archiv oder Wissensspeicher sprechen? Wächst da eine Geschichtskonkurrenz heran, die mit alter DNA und stabilen Isotopen die Quellen und Deutungen der HistorikerInnen überbieten will? Lassen sich biologische Daten überhaupt soziokulturell interpretieren? Ist es zulässig, zum Beispiel Haplotypenverteilungen mit Populationen, geografischen Räumen oder sogar archäologischen Kulturen, also Verbreitungen bestimmter Sachguttypen, in Verbindung zu bringen? Droht hier nicht Biologismus und gerät nicht der mühsam erkämpfte Konstruktivismus der Geschichtswissenschaften in Gefahr? ${ }^{1}$

Eine Vielzahl überfachlich besetzter Workshops und einige Diskussionsveranstaltungen geisteswissenschaftlicher Einrichtungen mit Protagonisten der aDNA-Forschung der letzten beiden Jahre belegen die neue Aufmerksamkeit der Geschichtswissenschaft, aber auch ihre Sorgen und Wissensdefizite. ${ }^{2}$

Am Jenaer MPI widmen sich unter der Leitung des Genetikers Johannes Krause, des Linguistikers Russell Gray sowie der Molekularbiologin und Archäologin Nicole Boivin ForscherInnen aus über einem Dutzend Herkunftsfächern der „Geschichte der Menschheit unter Verwendung modernster analytischer und genetischer Methoden." Sie arbeiten, so heißt es auf der Website des Instituts, an „grundlegende[n] Fragen zur biologischen und kulturellen Entwicklung des Menschen von der Steinzeit bis heute". Somit schließt das MPI-SHH zeitlich an den Aufgabenbereich des Leipziger MPI für evolutionäre Anthropologie an. Nun erhalte „die Evolutionswissenschaft einen Ort, an dem Fragen zur Entwicklungsgeschichte vielfältiger biologischer und kultureller Phänomene" mit vor allem naturwissenschaftlichen Methoden bearbeitet werden (MPI 2016b). Sein Interesse an NachwuchswissenschaftlerInnen aus Geschichte und Archäologie demonstrierte das MPI für Menschheitsgeschichte im Mai 2016, indem es diese zum Workshop unter dem Titel „Neue Methoden in Archäologie und Geschichtswissenschaften" einlud, um ihnen die am Institut eingesetzten Verfahren näher zu bringen und einen Dialog zu schaffen, „in dem Geistes- 
und Naturwissenschaftler gemeinsam über die Möglichkeiten und Grenzen einer solchen transdisziplinären Kooperation nachdenken" (MPI 2016a).

Von den tatsächlichen oder antizipierten Schwierigkeiten solcher Kooperationen zeugen jedoch nicht nur die genannten Diskussionsveranstaltungen, die übrigens auch nicht auf den deutschsprachigen Raum beschränkt sind, wie ein entsprechender Roundtable der American Historical Association unter dem Titel History Meets Biology 2014 zeigte ([o.V.] 2014: 1492, 1494). Jüngst wurde auch in einem Editorial in Nature über jene Geschichtsschreibung berichtet, für die vor allem deutschsprachige (Wissenschafts-)historikerInnen und die Science and Technology Studies den Begriff der Genetischen Geschichte bzw. Genetic History geprägt haben:

[...] a new breed of scientists is trying to muscle in on the work of the present. These researchers want to use modern genetic techniques to answer historical questions, and as they do so, they are firmly treading on the toes of their colleagues in the humanities. These geneticists promise answers: using analysis of DNA to discover what „really“ happened during the Bronze Age and the Viking sagas and replace „biased“ histories with cold, hard data ([o.V.] 2016: 437-438).

Wirklich neu ist das Forschungsfeld, das solche Sorgen auslöst, nicht. Es geht bis in die 1960er Jahre zurück, als die Evolutionsforschung, die immer als historische Forschung konzipiert war, um die molekulare Ebene erweitert wurde. Damals waren lediglich alte Moleküle technisch weitgehend unzugänglich. Einzelne WissenschaftlerInnen aus der Genetik, Evolutionsforschung und biologischen Anthropologie, die sich mit den Menschen in der Vergangenheit auseinandersetzen, verstanden sich ausdrücklich auch als HistorikerInnen (Sommer 2012: 377; Feuchter 2014). Eine Genetische Geschichte Europas skizzierten der italienische Populationsgenetiker Luigi Luca Cavalli-Sforza und der Archäologe Albert J. Ammerman schon 1984 im Buch The Neolithic Transition and the Genetics of Populations in Europe.

Das Interesse der Geschichtswissenschaft an diesem Feld kommt spät und lässt sich wohl am ehesten mit den geringen institutionellen akademischen Berührungspunkten mit der Paläogenetik, prähistorische Anthropologie, Evolutionsbiologie und anderen beteiligten Fächern erklären. In den deutschen Massenmedien jedoch sind verschiedene Fragestellungen und Protagonisten wie der am MPI in Leipzig forschende Evolutionsgenetiker Svante Pääbo überaus präsent. Allein $45 \mathrm{Mal}$ berichtete SPIEGEL online seit 2000 über den „Neanderthal Man“ Pääbo und seine Studien zur genetischen Verwandtschaft von Neandertalern und Anatomisch Modernen Menschen. ${ }^{3}$

Seit etwa zwanzig Jahren beteiligen sich vor allem prähistorische ArchäologInnen (Ur- und Frühgeschichte) in konkreten Kooperationspro- 
jekten an diesem Forschungsfeld. Zu einem großen Teil sehen diese sich selbst als historische KulturwissenschaftlerInnen (Eggert 2005: 227; Veit 2011: 299-300). Sie diskutieren im überfachlichen Miteinander seit Jahren jene epistemologischen und fachpolitischen Fragen, die nun auch die Geschichtswissenschaft, und hier insbesondere die Mediävistik, beschäftigen. Einige ArchäologInnen und nicht molekularbiologisch arbeitende AnthropologInnen befürchteten zum Beispiel, dass Evidenzen der Genetik ihre Quellen und Erkenntniswege diskreditieren und historische Fächer aus ihren angestammten Kompetenzbereichen verdrängen könnten. ${ }^{4}$ Vor allem seit der Mitte der 2000er Jahre haben ArchäologInnen gezielt Anstrengungen unternommen, um sich Wissen über die epistemologischen, methodischen und fachpolitischen Charakteristika der je anderen anzueignen und dieses mit den Bedingungen und Logiken des eigenen Herkunftsfachs in Verbindung zu setzen. Es gebe, so die Kulturwissenschaftlerin Stefanie Samida und der Prähistoriker Manfred K.H. Eggert 2013 in ihrer "Streitschrift" Archäologie als Naturwissenschaft reichlich Anlass über disziplinäre Identitäten und das spezifische Wissen und Können der Archäologie im Vergleich zu den Naturwissenschaften zu sprechen (Samida \& Eggert 2013; Experteninterview Eggert 2013). Sie beschäftigt die Frage, wie die prähistorische Archäologie historische Kulturwissenschaft sein und zugleich neue naturwissenschaftliche Quellen und Expertise integrieren kann.

Im überfachlichen Miteinander sind Debatten an der Tagesordnung über die jeweiligen Kriterien guter wissenschaftlicher Arbeit und über die methodischen Probleme, die auftreten, wenn biologische und Artefaktquellen, genetische Daten und archäologische Befunde miteinander in Bezug gesetzt werden sollen. NaturwissenschaftlerInnen, so eine Befürchtung, könnten vorschnell behaupten, über Gewissheiten oder hard facts zu verfügen, und ArchäologInnen würden dies womöglich in einer Art Selbstpreisgabe noch fördern, indem sie die genetischen Quellen höher bewerteten als die eigenen (Expertinneninterview Samida 2013). In der Tat gibt es VertreterInnen der deutsch- und englischsprachigen Archäologie, die diese Art von „hard science“ (Soren 2003: 203) für die Geschichts- und Kulturwissenschaften herbeiwünschten, weil sie sich davon Erkenntnisvorteile und eine inhaltliche Modernisierung der Fächer erwarteten. ${ }^{5}$ Dies wiederum ruft Abwehrreaktionen und Besorgnis bei denjenigen hervor, die die letzte Sinnstiftung in kooperativen Projekten als Reservatrecht der historischen Wissenschaften betrachten: Den naturwissenschaftlichen PartnerInnen fehle das dafür nötige Kontext- und Methodenwissen und das Wissen um die historische Gewordenheit von soziokulturellen Konzepten wie Kultur, Migration oder gar Ethnizität (Samida \& Eggert 2013: 24; Pluciennik 1996: 14; Rüdiger Krause in Bienert et al. 2009: 40; Pohl 2016). Anlass 
zu solchen Befürchtungen gaben konkrete Kooperationsprojekte und Veröffentlichungen (dazu Eggert 2016), die auf überfachlichen Tagungen zur Sprache kamen, deren Ziel es war, genau solche Divergenzen aufzudecken und miteinander zu besprechen (etwa Claßen \& Schön 2014; Samida \& Feuchter 2016). Zwar bestehen die Verhandlungen darüber, wer und mit welchen Quellen die Vergangenheit am besten erklären kann, auch weiterhin oft noch in Debatten darüber, wer sich in der akademischen Praxis wem unterordnen und wer die Hoheit über das geschichtliche Narrativ haben soll. Dennoch plädieren inzwischen die meisten Beteiligten für partnerschaftliche Kooperation und integriertes Vorgehen von der Projektplanung an über ein gemeinsames kontinuierliches Wissensmanagement bis zur Dateninterpretation (z. B. Samida \& Eggert 2013: 26).

Die insgesamt spürbare wachsende Offenheit der ArchäologInnen für genetische Quellen, molekularbiologische Expertise oder populationsgenetische Szenarien ist eben nicht per se unkritisch oder naiv. Und umgekehrt haben GenetikerInnen anfängliche Gewissheitsversprechungen ebenso zurückgenommen wie die in der euphorischen Anfangsphase der 1990er Jahre geäußerte Vorstellung, die wesentlichen Forschungsfragen der Archäologie und Anthropologie, selbst der Evolutionsforschung, in Zukunft auf molekularem Wege beantworten zu können. Auch wenn sie dies selten in der geschichtswissenschaftlichen Begrifflichkeit tun, erkennen sie an, dass molekulare Quellen im Wesentlichen die gleichen Charakteristika und Beschränkungen aufweisen wie alle anderen Quellen auch - Selektivität, Perspektivität, Standortgebundenheit. Nur in technischer, aber nicht in grundsätzlicher Hinsicht unterscheiden sich deshalb die Anforderungen an Quellenkritik und -interpretation. GenetikerInnen haben jüngst selbst sehr deutlich gemacht, dass der Wert der Quelle von der jeweiligen Fragestellung abhängt und alte DNA kein Allheilmittel darstellt, sondern sehr prinzipielle Aussagegrenzen besitzt (z. B. Experteninterview Krause \& Haak 2016; Experteninterview Burger 2013).

\section{Vorgehensweise und Quellen}

Dieser Beitrag geht der historischen Gewordenheit des epistemischen Objekts alte DNA und des überfachlichen Forschungsfelds nach, das sich seit den 1980er Jahren mit ihr befasst. Die wissenschaftshistorische Perspektive kann in der im Moment unter dem Stichwort genetic history hoch normativ geführten Diskussion über Schaden und Nutzen des Einsatzes von molekulargenetischen Verfahren zur Bearbeitung historischer Fragestellungen nur von Nutzen sein. 
Vorwegzunehmen ist: genetic history bzw. Genetische Geschichte sind Wortschöpfungen, die das Phänomen „von außen“ beschreiben sollen (Samida \& Feuchter 2016) und darauf abheben, dass Körpersubstanzen auf neue Weise zu Geschichtsträgern werden. ${ }^{6}$ Im Feld selbst werden sie selten benutzt. Andere Bezeichnungen, wie Molekulare Archäologie oder Paläogenetik, sind im Forschungsfeld selbst entstanden. Nomenklaturen wie aDNA-Forschung, genetic archaeology, molecular anthropology oder Paläopopulationsgenetik sind weder identisch, noch gehen sie ineinander auf weder in Deutschland, noch international. Eine Schnittmenge haben diese Forschungsfelder und -perspektiven darin, dass sie erstens molekulargenetische Verfahren - neben anderen naturwissenschaftlichen Verfahren einsetzen, um - neben einigen anderen - im weitesten Sinne historische Fragen zu klären. Das gemeinsame Besondere und das Neue daran ist, dass sie zweitens nicht mehr nur ganze Organismen oder Zellen, mit denen sich zum Beispiel Anthropologie und die Archäologie schon länger unter historischer Fragestellung befasst haben, sondern Moleküle zur Quelle erklärt haben.

Das folgende erste Kapitel führt den Begriff aDNA ein, das zweite charakterisiert die aDNA-Forschung als überfachliches wissenschaftliches Feld: WissenschaftlerInnen aus unterschiedlichen Fächern und Wissenschaftskulturen kamen über alten Molekülen zusammen, von denen sie sich Informationen über (evolutions-)historische, populationsgenetische, epidemiologische und weitere Prozesse und Sachverhalte erhofften. Der Entstehung und Entwicklung dieses Feldes ist das dritte Kapitel gewidmet. Der Fokus liegt auf den methodischen und epistemologischen Grenzen der aDNA-Forschung und insbesondere auf dem Problem der Authentifizierung von DNA-Daten. Deutlich wird aber auch, wie DNA zur Quelle für im weitesten Sinn historische Fragestellungen deklariert, wie sie im Labor und am Rechner hergestellt wird und wie ihre Aussagechancen und -grenzen abgesteckt werden. Das vierte Kapitel geht überfachlichen Diskussionen über die Möglichkeiten nach, genetische und sozio-kulturelle Konzepte zueinander in Bezug zu setzen. aDNA-Forschung ist zwar ein junger Untersuchungsgegenstand, doch die wissenschaftliche Wissensproduktion lässt sich mit den Methoden der Geschichtswissenschaft grundsätzlich historisieren, gleichgültig wie nah oder fern die untersuchte Vergangenheit ist. Doing history ist letztlich nur eine bestimmte Art, die Welt zu sehen. Die Untersuchung steht vor der Herausforderung aller zeithistorischen Studien: Langfristige Folgen und Wirkungen lassen sich nicht überblicken. Jede wissenschaftshistorische Untersuchung der Gegenwart steht vor diesem Interpretationsproblem, das der amerikanische Historiker Michael D. Gordin so charakterisierte: 
This wonderful instability of science-in-the-making raises concerns about how confident we can be when we draw on contemporary science in formulating historical arguments. How can we historians be confident, when biologists themselves are not? ${ }^{7}$

Gordin bezog sich auf die Schwierigkeit, die von den Biowissenschaften generierten Daten in sozial-, medizin- oder kulturhistorische Narrative einzubeziehen. Doch gilt das Gesagte analog auch für die wissenschaftshistorische Untersuchung dieser Wissenschaften selbst. Gerade Wissenschaftsund Technikgeschichte haben aber Erfahrung damit, dass viele Theorien, Ansätze oder Moden wieder verschwanden, ihre Bedeutung verloren oder änderten. Insofern steht einer wissenschaftshistorischen Perspektive auf die aDNA-Forschung nichts Prinzipielles entgegen. Im Gegenzug ist das Quellenmaterial sehr reichhaltig und oft gut zugänglich. Das Sample umfasst rund 1.400 Texte aus der täglichen wissenschaftlichen Produktion: ${ }^{8}$ Originalartikel, Reviews, Sammelbände, Handbücher, Rezensionen, Tagungsberichte, calls for papers, Tagungsprogramme, Websites, Poster, Vorträge, autobiografische Berichte und vieles mehr. Inhaltsanalysen, Metaphernanalysen und bibliometrische Auszählungen wurden kombiniert. Nicht publiziertes Material, etwa Forschungsanträge, Gutachten, Laborbücher oder Grabungsjournale, waren jedoch nicht zugänglich. Offene ExpertInneninterviews auf der Basis von Leitfäden schlossen diese Lücke teilweise (vgl. zur Methode Meuser \& Nagel 2009). Sie ermöglichten Verknüpfungen zwischen den gedruckten Quellen und Einblicke in den Forschungsalltag. Jedoch führte nur ein Teil der Interviews aus fachpolitischen und persönlichen Rücksichten zu zitierfähigem Material. Ein nationaler Untersuchungsschwerpunkt war nicht praktikabel, denn Charakteristika des Feldes in der Gegenwart sind seine internationale Vernetztheit und sein hoher Spezialisierungsgrad.

\section{Was ist ancient DNA?}

Hinter dem Begriff aDNA verbergen sich Reste von Molekülen aus toten Organismen, also Menschen, Tieren, Pflanzen und Mikroorganismen. Stirbt ein Organismus, verfällt seine DNA. Wie und vor allem wie schnell dies passiert, hängt von Temperatur, pH-Wert, Feuchtigkeit und Mikrobenbefall des Liegemilieus ab. Unter optimalen Bedingungen haben sich DNAMoleküle in über 700.000 Jahre alten fossilen Knochen erhalten (Orlando et al. 2013: 74-78). Degradierte DNA weist typische Schadensmuster auf und ist höchst anfällig für Kontaminationen mit exogener DNA. Da es we- 
niger auf das Alter als auf den physischen Zustand der Moleküle ankommt, trifft der in der Forensik übliche Begriff degradierte DNA sehr gut. In dem Feld, das im Folgenden vorgestellt wird, haben sich aber die Bezeichnungen ancient DNA und aDNA durchgesetzt. Im deutschsprachigen Raum ist auch von alter DNA die Rede.

Zu beachten ist, dass nicht „die DNA“ oder "das Gen“ die eigentlichen Quellen sind, sondern Varianten von Basenabfolgen an bestimmten Orten der DNA und deren Veränderungen über die Zeit. Diese DNA-Daten werden im Labor und am Rechner geschaffen, sind also das mit technischen Mitteln geschaffene Produkt menschlichen und damit sozialen und kulturellen Handelns und so in hohem Maße standortgebunden. Die molekulargenetischen Verfahren liefern Daten, nicht Geschichte. DNA-Daten sind wie alle anderen Quellen nur Vergangenheitsspuren und als solche selektiv und perspektivisch. Wie aus den Daten Geschichte wird, in welchem Verhältnis die Quellen zueinander stehen und wer die historischen Narrative entwickeln darf, handeln WissenschaftlerInnen miteinander aus. Der Unterschied zur traditionellen Geschichtsforschung besteht darin, dass ein Großteil der beteiligten ForscherInnen keine geschichtswissenschaftliche Ausbildung mitbringt.

Das Probenmaterial stammt aus archäologischen und anthropologischen Grabungen, Sammlungen und Museen. Mitunter sind gezielte de novo Grabungen möglich. Häufiger jedoch muss auf vorliegendes Material zurückgegriffen werden. Die epistemischen Ressourcen der Archäologien und der Anthropologien sind begrenzt und damit auch die potentiell für DNA-Analysen in Frage kommenden Funde. Diese Begrenztheit reguliert, welche und wie die Forschungsfragen gestellt werden, welche Anwendungen möglich sind und wie groß die Reichweite der Ergebnisse ist. Häufiger als die für die Laborwissenschaften typischen hypothesengeleiteten Forschungsdesigns sind deshalb materialgeleitete Zugänge. Untersuchen lässt sich nur, was geborgen wurde. ${ }^{9}$ Funde stellen aber stets einen winzigen Bruchteil der theoretisch möglichen Überlieferung dar, und ein Bruchteil von ihnen wiederum liegt in einem physiologischen Zustand vor, der eine DNA-Analyse erlaubt. Die Samples sind deshalb oft klein, auch wenn die neuesten Sequenzierungsverfahren riesige Mengen an Sequenzdaten pro Probe hervorbringen können. Konservatorische Bedenken begrenzen die Materialbasis zusätzlich. Nicht immer liegen die nötigen Kontextinformationen zum Fund, insbesondere gesicherte Datierungen, vor. Dies kann den Aussagewert der Quelle erheblich reduzieren. Feldarchäologie und Sammlungswesen beinhalten grundsätzlich diverse Auswahlentscheidungen und sind vielfach kulturell gebunden - ebenso wie die Molekularbiologie und andere Laborwissenschaften. So kommt demnach kein Fund, weder eine Sachgutquelle, noch der Überrest eines Organismus, „neutral“ in die Welt. 
DNA-Daten sind nicht grundsätzlich objektiver oder generalisierbarer als andere Quellen. Das Material erzwingt auch sich keineswegs die eingangs angesprochenen, befürchteten Quellenhierarchien, und die aDNA-Forschung bringt wie alle Wissenschaften in vielerlei Hinsicht perspektivisch gebundenes Wissen hervor.

Molekulare Quellen werden wie andere auch von Menschen zum Sprechen gebracht und erzeugen aus sich selbst keine Erkenntnis. Worin das Aussagepotential einer DNA-Quelle besteht, hängt davon ab, welche DNA untersucht wird. Nicht immer ist es „alte“ DNA, denn bestimmte paläogenetische und evolutionsgeschichtliche Fragestellungen werden auch mithilfe von modernen DNA-Sequenzen bearbeitet. Diese dienen einerseits dem Vergleich mit „alten“ Daten, andererseits kann aus ihnen auf genetische Prozesse in der Vergangenheit zurückgerechnet werden. In der DNA heute lebender Organismen ist, so lässt sich argumentieren, die genetische Vergangenheit ihrer Vorfahren dokumentiert. ${ }^{10}$ Doch sind viele genetische Merkmale über die Zeit durch statistische Ereignisse und Selektion verloren gegangen, was Studien zur Entwicklung genetischer Variationen und phylogenetischer Beziehungen innerhalb von und zwischen genetischen Einheiten erschwert (Shapiro et al. 2008: 210-211). Ist alte DNA zugänglich, kann zudem der Parameter Zeit besser integriert werden.

Des Weiteren kommt es darauf an, ob nukleare oder mitochondriale DNA untersucht wird und welche Markersysteme gewählt werden. Nukleare DNA (nDNA) aus dem Zellkern ist hochspezifisch und geeignet, Individuen genetisch zu identifizieren, ihr chromosomales Geschlecht zu bestimmen und genetische Verwandtschaftsgrade zwischen Individuen und Gruppen zu untersuchen. Ihre Erhaltungschancen sind jedoch besonders gering. Mitochondriale DNA (mtDNA) stammt aus den Mitochondrien, den Zellkomponenten, die den Energiestoffwechsel der Zelle organisieren. Ihre Erhaltungswahrscheinlichkeit ist höher, weil mtDNA in vielfacher Kopienzahl vorliegt. Sie wird matrilinear, das heißt in der mütterlichen Linie, vererbt und über Generationen hinweg mit geringen Veränderungen weitergegeben (Brown \& Brown 2011: 23-24, 173-178). Die Veränderungsraten lassen sich errechnen. mtDNA eignet sich beispielsweise, um Spezies voneinander $\mathrm{zu}$ unterscheiden oder um zu untersuchen, ob einzelne Individuen in mütterlicher Linie genetisch verwandt waren. Damit lassen sich lange genetische Prozesse innerhalb und zwischen Gruppen verfolgen. Da mtDNA in technischer Hinsicht das leichter zugängliche bzw. häufiger erhaltene Material darstellt, war sie das wissenschaftliche Objekt, das die aDNA-ForscherInnen in den 1980er Jahren zuerst anvisierten. Sollen auch die paternalen Abstammungsbeziehungen und komplexere horizontale Fragestellungen untersucht werden, ist nDNA nötig. ${ }^{11}$ 
Untersucht werden die Allele, das heißt die möglichen Varianten von Basenabfolgen an bestimmten Orten (Loci) der DNA. Vergleicht man die Allelmuster einzelner Individuen, lassen sich Aussagen über deren genetisches Verhältnis zueinander treffen. Untersucht man die Veränderung und Verbreitung bestimmter Allelfrequenzen bei einer größeren Anzahl von Individuen über die Zeit, lassen sich evolutionshistorische und -genetische Fragestellungen in der longue durée bearbeiten. Bei Untersuchungen zu genetischem Geschlecht oder Spezies verhält es sich ähnlich: Marker an bestimmten Genloci sind die Quelle.

Überwiegend werden nicht-codierende Abschnitte der DNA herangezogen, das heißt Regionen, die nicht an der Proteinsynthese beteiligt sind. ${ }^{12}$ Auf die codierenden Abschnitte, die Gene, wird unter (evolutions-) historischer Fragestellung eher selten zurückgegriffen. Es ist aber grundsätzlich möglich, zu untersuchen, ob ein bestimmtes Gen in der Vergangenheit vorlag und wie es $\mathrm{zu}$ einem bestimmten Zeitpunkt aussah. ${ }^{13}$ Aussagen zum Phänotyp werden selten versucht, da diese auf einem komplizierten Miteinander von Erbanlagen und Umwelteinflüssen beruhen. Der Genotyp determiniert nur in den seltensten Fällen direkt und eindeutig ein bestimmtes phänotypisches Merkmal. Die meisten phänotypischen Merkmale sind überdies polygen, das heißt mehrere Gene sind an ihrer Entwicklung beteiligt.

\section{Was ist aDNA-Forschung?}

Angesichts der neuen und alten Begriffe im Feld - molecular anthropology, aDNA-Forschung, Archäogenetik, bioarchaeology, pal(a)eo(population) genetics und viele mehr - lässt sich aDNA-Forschung am besten sich das Phänomen als kollektiver Produktionsprozess von im weitesten Sinn historischem Wissen auf der Basis von (alter) DNA ansprechen. Aus einem anfänglichen Interesse an (alten) DNA-Molekülen, das Beteiligte aus diversen Forschungsfeldern und Fächern der Natur-, Kultur- und Geisteswissenschaften teilten, entstand um die als Quelle definierte DNA herum ein Ensemble von Verfahren, Methoden, Fragen und Forschungswegen, das wiederum Beteiligte aus einer Vielzahl von Bereichen nun betreiben.

Überfachlichkeit, Internationalität und Heterogenität sind Charakteristika des Feldes. Ob eine aDNA-Forschung per se existiert, ist umstritten, und der Stellenwert der DNA-Quellen im jeweiligen Forschungsgebiet oder Fach ist sehr unterschiedlich. PopulationsgenetikerInnen beispielsweise arbeiten mit DNA - ob sie alt oder rezent ist, ob sie aus archäologischen Funden stammt oder von lebenden Personen, ist nur in methodi- 
scher Hinsicht bedeutsam. Demgegenüber spielen in der bioarcha(e)ology aDNA-Analysen eine zwar nicht unwichtige, aber untergeordnete Rolle neben traditionellen Artefaktquellen und Methoden sowie neuen Labormethoden wie Isotopengeochemie, Spurenelement- und Proteinanalyse. In Paläoanthropologie, Paläobotanik und Paläozoologie haben DNA-basierte Verfahren einen bedeutenden Platz neben den morphologischen Verfahren eingenommen, diese aber nicht abgelöst. Mitunter wurde die aDNA-Kompetenz bestehenden Forschungsgebieten als Spezialisierung zugeschlagen, so zum Beispiel der Archäometrie, dem überfachlich organisierten Feld, in dem die verschiedensten archäologischen Quellenmaterialien mit naturwissenschaftlichen Verfahren analysiert werden. Teils kam es zu neuen Wortschöpfungen (archaeogenetics), teils wurden molekulare Verfahren nicht nur in die Arbeit, sondern auch in den Namen bestehender Gebiete integriert (Molekulare Anthropologie). Einige Nomenklaturen sind seit den 1960er Jahren in diskursiven Prozessen in einer Art „Sich-Ein-undAusrichten" auf Molekülen entstanden. Bei aller Diversität spricht jedoch eine ganze Reihe von ForscherInnen von aDNA-Forschung oder aDNA research und meint damit eine seit den späten 1980er Jahren bestehende lockere Community. ${ }^{14}$

Nur wenige sprechen von einem Fach (Willerslev \& Cooper 2005: 5). Es gibt weder einen fest umrissenen gemeinsamen Gegenstand und ausgewiesene Professuren, noch eigene Journals mit längerer Erscheinungsdauer, Fachstudiengänge oder spezifische wiederholbare Karrierewege. Eine aDNA-Fachidentität lässt sich gegenwärtig nicht erkennen. Vielmehr werden Methoden, Techniken und manche Fragestellungen über die Grenzen von Spezialbereichen, Fächern und Disziplinen hinweg für gültig erklärt. Wissenschaftliche Einheiten haben Verknüpfungsmöglichkeiten für sich erkannt. Ein Teil der jüngeren ForscherInnen verfügt über Mehrfachqualifikationen, und einige verstehen sich als Grenzgängerinnen oder Brückenbauer zwischen Fächern und Wissenschaftskulturen. ${ }^{15}$ Prähistorische AnthropologInnen beispielsweise beanspruchen für sich, sowohl natur- als auch geisteswissenschaftlich zu arbeiten und historisch Sinn zu stiften, und begründen dies mit ihrer Kompetenz für beide Wissenschaftswelten (Herrmann 1997: 100; Pusch \& Scholz 1999: 374; Henke 2010b: 89-90). Besonders selbstbewusst gehen die eher in den Naturwissenschaften verankerten Beteiligten mit fachlichen Zuordnungen um. Johannes Krause beispielsweise sagt von sich, er sei vom Studium her ein Biochemiker, der bei Svante Pääbo am Leipziger MPI in der evolutionären Anthropologie arbeitete, dabei zum evolutionären Genetiker wurde, zuerst eine Professur für Umweltarchäologie und dann eine für Archäo- und Paläogenetik erhielt und nun am Jenaer MPI die Abteilung Archäogenetik leite. Sein Arbeitsgruppenleiter Wolfgang Haak verdeutlichte im Interview: 
Das ist ja schon irgendwie der Tatsache geschuldet, dass wir alle irgendwie Nebeneinsteiger sind. Also wir haben Kollegen, die sind Physiker, Mathematiker, Bioinformatiker, dann gibt's Leute, die sind Archäologen oder Anthropologen, und dann natürlich auch die klassischen Biologen und Genetiker. Also das kommt aus allen Ecken zusammen und bildet dann eins. Und wir können diese Entität natürlich field of ancient DNA nennen, aber letztendlich speist sie sich aus anderen Disziplinen. Und die Disziplinenfrage, die lässt mich eigentlich auch kalt irgendwo. Also es macht Spaß so zwischen den Stühlen (Experteninterview Krause \& Haak 2016).

Bezweifelt wird aber in der Regel, dass jemand in zwei oder mehr der hochspezialisierten Fächer gleichermaßen qualifiziert sein kann (Harbeck 2012: 200; Experteninterview Burger 2013; Experteninterview Krause \& Haak 2016).

Aus Molekularbiologie, Biochemie, medizinischer Molekulargenetik und Forensik stammen in der Regel die Methoden und Techniken, um DNA zu isolieren, reinigen, amplifizieren, sequenzieren und analysieren. Sie sind meist grundsätzlich generalisierbar genug, um auch mit alter und degradierter DNA zu funktionieren, doch ist es erforderlich, sie zu modifizieren und weiterzuentwickeln. Das Probenmaterial liefern vor allem die universitäre Archäologie, Botanik, Zoologie und Anthropologie sowie Denkmalpflege und Museen.

Zunehmende Bedeutung kommt Bioinformatik, Mathematik und Statistik zu - insbesondere bei populationsgenetischen Fragestellungen. Ihre Aufgabe ist es, Big Data handhabbar zu machen. Heute sind, dank der seit der Mitte der 2000er Jahre entwickelten hocheffizienten Verfahren des Next Generation Sequencing, nicht nur Studien mit stark beschädigter DNA möglich, sondern sogar Untersuchungen ganzer Genome oder sehr großer Teile davon (Mathieson et al. 2015; Allentoft et al. 2015). Dies führt $\mathrm{zu}$ riesigen Sequenzdatenmengen und weltweit wachsenden Datenbanken (Knapp \& Hofreiter 2010: 229-238; Shapiro et al. 2008: 233).

aDNA-Forschung findet in international organisierten Netzwerken statt, in denen äußerst kompetitive Forschungseinheiten kooperieren und konkurrieren. Sie arbeiten unter unterschiedlichen Frage- und Zielstellungen mit alter DNA und diversen anderen epistemischen Objekten wie etwa Proteinen oder stabilen Isotopen. Die für die Wissenschaften der Gegenwart charakteristische Dualität von Spezialisierung und Globalisierung ist deutlich erkennbar. aDNA-Forschung ist ein kooperatives Unterfangen und lässt sich nicht als Ein-Personen-Projekt, sondern nur in Form von teils umfangreichen Arbeitsgruppen an eigens eingerichteten aDNA-Laboren betreiben, denen ProfessorInnen, wissenschaftliche MitarbeiterInnen, Stu- 
dierende, studentische Hilfskräfte und technisches Personal angehören. Am Centre for Geogenetics des Natural History Museum of Denmark beispielsweise, einem der momentan größten und wichtigsten Labore, gehören der Gruppe von Eske Willerslev gegenwärtig 25 Personen an, der Gruppe von M. Thomas P. Gilbert 44 Personen und der Arbeitsgruppe von Ludovic Orlando 15 Personen (Natural History Museum of Denmark 2016).

Forschungskooperationen und Zitiernetze verlaufen eher international als national. Ihre Knotenpunkte und die wichtigen Labore befinden sich in den USA, Dänemark, Großbritannien, Deutschland und Australien, dort überwiegend an Universitäten, teils aber auch an Museen oder außeruniversitären Forschungseinrichtungen wie insbesondere an den genannten Max-Planck-Instituten in Leipzig und Jena.

Die Mehrzahl der bearbeiteten Fragestellungen ist populationsgenetisch, bioarchäologisch oder (evolutions-)historisch, doch auch Naturschutzbiologie, Biodiversitätsschutz und Rechtsmedizin setzen auf die Methoden und Erkenntnisse der aDNA-Forschung. Ein Spezialgebiet stellt die Paläoepidemiologie dar, in der Vergangenheitswissen über die Ursprünge von Krankheiten, die Evolution und Diversität der Pathogene sowie über deren Verbreitung nicht nur qua eigenen Rechts, sondern auch im Hinblick auf gegenwärtige und zukünftige medizinische Anwendungen generiert wird. Von Erkenntnisinteressen und Fragestellungen hängt ab, welche Fächer sich jeweils über der alten DNA begegnen und welche Rolle die Beteiligten dann einnehmen. Steht eine größere (populations-)genetische Frage im Vordergrund, ist die Funktion der ArchäologInnen oft auf die Materiallieferung beschränkt (mit weiteren Nachweisen Pickrell \& Reich 2014; Lazaridis et al. 2014; Krause et al. 2010). Geht es um „kleinere“ Fragestellungen, wie etwa die molekulare Bestimmung des genetischen Geschlechts oder der Verwandtschaftsbeziehungen einzelner Individuen, kooperieren hingegen oft auf lokaler Basis ArchäologInnen und in molekularen Verfahren versierte AnthropologInnen oder ZoologInnen (Haak et al. 2010). In solchen Fällen stellen die aDNA-Verfahren angesichts ihres Aufwands ohnehin oft Ersatzlösungen dar, wenn morphologische Verfahren nicht eingesetzt werden können.

PopulationsgenetikerInnen und EvolutionsforscherInnen, die sich für größere genetische Prozesse und längere Zeitläufte interessieren, erscheinen Einzelfallstudien, insbesondere zu einzelnen Herrscherpersönlichkeiten oder Verwandtschafts- und Abstammungsbeziehungen in außergewöhnlichen Kollektivbestattungen, wenig relevant (Pääbo et al. 2004: 670; Kirsanow \& Burger 2012: 124; Experteninterview Krause \& Haak 2016). Gerade diese Studien sind aber in den Breitenmedien sehr präsent, da sie sich gut massenmedial vermitteln lassen. ${ }^{16}$ Die mediale Präsenz einzelner 
Projekte und Forscherpersönlichkeiten wird von der Community aber vielfach kritisch gesehen und veritable Sanktionierungsversuche treffen diejenigen, die die selbstgesetzten Grenzen der beteiligten Wissenschaften überschreiten: Dies betrifft vor allem das kommerzielle ancestry testing, ${ }^{17}$ Unterhaltungsgenetik und populäre Herkunftserzählungen. ${ }^{18}$

\section{Die Entwicklung aDNA-Forschung}

Die Entwicklung der aDNA-Forschung lässt sich mit dem Hype Cycle gut beschreiben, einem Modell für den Lebenszyklus von neuen Technologien, das die Computerlinguistin Jackie Fenn in den 1990er Jahren aufgestellt hat. ${ }^{19}$ Als Einordnungsangebot für die Methodenentwicklung in den Archäologien wurde der Hype-Zyklus bereits genutzt, und zwar hinsichtlich der Geschichte des Einsatzes von Netzwerkanalysen, also einem weiteren Fall, in dem Methoden aus anderen Wissenschaften in die Archäologie eingebracht wurden. ${ }^{20}$ Dies ermutigt dazu, den Hype-Zyklus auch als Deutungsangebot für die aDNA-Forschung vorzuschlagen. Im HypeZyklus stößt ein technologischer Auslöser (Technology Trigger) auf großes fachliches und mediales Interesse, das im „Gipfel der überzogenen Erwartungen" (Peak of Inflated Expectation) mündet. Euphorisch wird Großes versprochen und einfache Lösungen werden in Aussicht gestellt. Derart überzogener Enthusiasmus mündet im „Tal der Enttäuschungen“ (Trough of Disillusionment), weil die Technologie die überhöhten Erwartungen nicht erfüllt. Während die Berichterstattung zurückgeht und viele Beteiligte aufgeben, loten einige systematisch und selbstkritisch die Grenzen der Technik und ihrer Implementationen aus und begeben sich auf den Slope of Enlightenment. Über diesen „Pfad der Erleuchtung“ erreicht die Technologie ihr „Produktivitätsplateau“ (Plateau of Productivity).

Dieser Verlauf zeigt sich in der wissenschaftshistorischen Außenperspektive, er findet sich aber auch in dem Narrativ, das ProtagonistInnen der aDNA-Forschung wie Erika Hagelberg, Svante Pääbo und Martin K. Jones in Rückblicken zeichnen (Hagelberg et al. 2015; Pääbo 2014; Jones 2001; Hofreiter 2009).

Zugang zur molekularen Erkenntnisebene suchten Genetik, Evolutionsforschung und Teile der biologischen Anthropologie, Zoologie und Botanik seit den 1960er Jahren. Dies stand im Zusammenhang mit der zumindest teilweisen Hinwendung dieser und anderer Fächer zu den Labormethoden der Biochemie, Mikrobiologie und Molekularbiologie (Morange 1998: 183). Genetik und Geschichte waren bereits gedanklich verbunden, wurde doch in der Evolutionstheorie nach Darwin das Natürliche als etwas histo- 
risch Gewordenes aufgefasst. In der Erweiterung des naturgeschichtlichen Denkens auf das Kulturelle fanden demgegenüber Evolutionsmetaphern und -denken Eingang in die Geschichts- und Sozialwissenschaften. Das Genkonzept des österreichisch-französischen Biologen Emile Zuckerkandl und des physikalischen Chemikers Linus Pauling wiederum beinhaltete die Vorstellung, dass die Evolutionsgeschichte in der DNA aufgezeichnet sei (Sommer 2008: 115 über Zuckerkandl \& Pauling 1965). Technisch zugänglich waren zuerst jedoch nicht die DNA-Moleküle selbst, sondern nur die Proteinsequenzen, die sie codieren.

Im Lauf der 1970er Jahre kamen rekombinante DNA-Technologien und die Sequenzierung von DNA-Molekülen, das heißt hier die Identifizierung der Abfolge von Basen auf dem DNA-Strang, auf (Sanger 1988: 20-25; dazu García-Sancho 2012: 49-64). 1981 war das menschliche mtDNA-Genom sequenziert und Daten über moderne Haplotypenverteilungen lagen vor. Auf diese technologischen Durchbrüche hatten Forscher wie der Biochemiker Allan C. Wilson am Labor für molekulare Evolutionsbiologie in Berkeley lange gewartet. Er hatte indessen Umwege über Blutserumproteine und Verfahren konzipiert, mit denen sich aus rezenten Daten auf Evolutionsereignisse zurückrechnen ließ. Am Anfang der 1980er Jahre setzte er seiner Gruppe das Ziel, nun einen Weg zu finden, für Fragestellungen zur Populationsgeschichte und Evolution direkt auf DNA - rezente oder wenn möglich auch alte - zuzugreifen. Er machte sein Labor zur Kaderschmiede der molekular arbeitenden Evolutionsforschung. Hier entstand 1987 das Konzept der Mitochondrial Eve (Cann et al. 1987: 35), das auf der Basis rezenter mtDNA-Daten einen Ursprung der Anatomisch Modernen Menschen Europas in Afrika nahelegte. Deutlich wird, dass Moleküle zugänglich gemacht werden sollten, um bereits seit Langem bestehende, überfachlich diskutierte Fragestellungen, hier eben die Human-OriginsFrage, neu zu bearbeiten.

$\mathrm{Zu}$ diesen Forschungsproblemen gehörte auch die Neolithisierungsfrage, also die Frage, ob der Übergang von der nomadisch-aneignenden Lebensweise der Wildbeuter und Sammler zur sesshafteren Lebensweise der Viehalter und Feldbauern in der Jungsteinzeit mit einer signifikanten Bevölkerungsbewegung einherging, oder ob statt Menschen nicht eher Wissen, Können und Artefakte wanderten. Diese Frage hofften der italienisch-amerikanische Genetiker Luigi Luca Cavalli-Sforza und der Archäologie Albert Ammerman mithilfe der allmählich vorliegenden Sequenzdaten moderner EuropäerInnen in den 1980er Jahren zu entscheiden. Sie argumentierten, dass sich die Häufigkeitsverteilung von Allelen in diesen Sequenzen geografisch und soziokulturell interpretieren lasse (Ammerman \& Cavalli-Sforza 1984, Kapitel 6). An diesen Versuchen wird erkennbar, dass die Molekularisierung der Genetik und Evolutionsforschung nicht nur grundlegend 
das Verständnis von Organismen und ihren Funktionsweisen veränderte, sondern auch das Denken über das Verhältnis dieser Organismen zu ihrer Umwelt beeinflussen sollte, da hier die Moleküle Auskunft geben sollten über einen sozialen und kulturellen Prozess. Doch es erwies sich trotz des wachsenden Corpus an ${ }^{14} \mathrm{C}$-Datierungen archäologischer Funde als problematisch, die aus rezenten DNA-Daten abgeleiteten genetischen Entwicklungen zu datieren. Cavalli-Sforza und Ammerman beklagten in ihrem 1984 erschienenen Buch The Neolithic Transition and the Genetics of Populations in Europe sehr, dass es keinen direkten Zugang zu paläolithischer oder neolithischer DNA aus archäologischen Funden gäbe, der es ermögliche, den Faktor Zeit sinnvoll einzuberechnen (Ammerman \& Cavalli-Sforza 1984: xiv, 138-139). Der Paläogenetik fehlte eine belastbare diachrone Perspektive.

Deshalb war das Ziel, DNA in alten Geweben nachzuweisen und im besten Fall daraus zu isolieren. Forensik, Biochemie und medizinische Genetik meldeten hier in den 1980er Jahren erste Experimente. Den ersten Erfolg erzielte Allan C. Wilsons Team um Russell Higuchi: Es isolierte DNA aus etwa 100 Jahre alten Museumspräparaten des Quagga, eines kleinen, ausgestorbenen Steppenzebras, und verglich sie mit rezenter Zebra-DNA (Higuchi et al. 1984). In evolutionsgeschichtlicher Hinsicht war der Vergleich wenig aufschlussreich. Entscheidend war vielmehr, dass überhaupt degradierte DNA gewonnen und untersucht worden war. Das Quagga steht deshalb am Anfang der meisten feldinternen Ursprungserzählungen, mit denen sich die aDNA-ForscherInnen ihrer eigenen Geschichte versichern.

Rasch folgte die nächste Sensation: 1985 meldete der schwedische Doktorand Svante Pääbo, von Haus aus Ägyptologe und Mediziner, dass es ihm im Alleingang gelungen sei, aDNA aus dem Weichgewebe einer spätantiken Kindermumie zu extrahieren und zu klonieren. Sein in Nature erschienener Artikel Molecular Cloning of Ancient Egyptian Mummy DNA (Pääbo 1985) zählt zu den meistzitierten Artikeln dieser experimentellen Phase. Zwar erwies sich Pääbos Experiment später als kontaminiert, doch hatte er prinzipiell den Weg zu alter DNA aufgezeigt. Dies begründete eine steile Forscherkarriere und machte ihn, in den Worten des englischen Bioarchäologen Martin Jones, zum "front runner in the race for ancient DNA“ (Jones 2001: 24). Innerhalb weniger Jahre wurde er aber auch zum „traffic policeman in a convoy moving with rather too much momentum for its own safety“ (Jones 2001: 25), denn Pääbo löste den Hype-Zyklus aus, war aber auch einer der ersten, die skeptisch wurden, Sensationsexperimente $\mathrm{zu}$ reproduzieren versuchten, und, als dies oft misslang, begannen, in akribischer Methodenarbeit systematisch die Chancen und Grenzen der Technik und ihrer Implementationen auszuloten. 
Mehrfach hat Martin Jones die zweite Hälfte der 1980er und frühen 1990er Jahre als „molecule hunt“ beschrieben (Jones 2001: 9): „By the end of the 1980s the race was on for the oldest DNA, and journals such as Nature and Science were poised at the finishing line" (Jones 2001: 9, 21). Das Motto dieser hastigen Anfänge war: „Schauen, was geht“: Wie lange und in welchem Material blieb DNA erhalten? Ließ sie sich aus jahrtausendealten Funden oder sogar aus Fossilen extrahieren? Wer gelangte an die älteste DNA? (Richards et al. 1995: 291-292; Waldron 1991: 155). Und was ließ sich eigentlich damit anfangen?

Der Zugang zu alter DNA versprach scheinbar, dass sich Geschichte nun (doch) als Laborwissenschaft betreiben und Prozesse der Vergangenheit menschliches Handeln ebenso wie genetische Entwicklungen oder Klimaveränderungen - im Labor erforschen ließen. Wilson und Pääbo sprachen 1989/1991 davon, die Evolution im aDNA-Labor nun auf frischer Tat zu ertappen („catch evolution red-handed“, Pääbo et al. 1989: 9709; Pääbo \& Wilson 1991: 45).

Mit großem technischen Optimismus, wie er am Anfang eines solchen Diffusionsprozesses auch zu erwarten war, versprachen insbesondere AnthropologInnen und GenetikerInnen einfache und haltbare Lösungen für diverse alte archäologische, anthropologische, paläopathologische, evolutionsbiologische und populationsgenetische Forschungsprobleme: Darunter waren der Ablauf der Besiedelung der Amerikas und Ozeaniens, die Entstehung der Anatomisch Modernen Menschen und ihre Verbreitung auf der Welt sowie die Phylogenien diverser ausgestorbener Arten (z. B. Krajewski et al. 1997; Hagelberg et al. 1994; Höss et al. 1994). Verknüpft war das vor allem im deutschsprachigen Raum mit großen fachpolitischen Zielen: Die biologische Anthropologie und Evolutionsforschung sollten zumindest teilweise zu Laborwissenschaften umgebaut, modernisiert und durch die Kompetenz für Moleküle innerhalb der nun von der Molekularbiologie dominierten Biologie aufgewertet werden. ${ }^{21}$ Der damalige Göttinger Institutsleiter Bernd Herrmann beschrieb noch einige Jahre später die (prähistorische) Anthropologie als ein von allen Seiten umzingeltes, sanierungsbedürftiges Gebilde, das in der Wissenschaftslandschaft um seine Legitimation ringe und es bei seiner molekularen Modernisierung nicht bei „nachahmende[m] Reagieren“ belassen dürfe, sondern risikofreudig vorgehen müsse (Herrmann 1997: 98). Im angelsächsischen Raum ging es hingegen mehr darum, Anthropology und Evolutionsforschung zu modernen Laborwissenschaften $\mathrm{zu}$ machen und sich von den morphologischmetrischen Methoden $\mathrm{zu}$ entfernen, die viele als veraltet und rassistisch empfanden. 
Legitim war experimentelle aDNA-Forschung in den Augen ihrer VertreterInnen auch schon deshalb, weil sie jetzt machbar war. Die Hoffnungen waren riesig:

It seemed that life's fundamental code could be recalled from the depths of geological time, and if that code could be recalled, whole living worlds could be contacted and viewed in meticulous detail (Jones 2001: 23).

In großer Begeisterung wurde eindeutiges, gewisses Wissen in Aussicht gestellt sowie der DNA Macht zu Wahrheit zugesprochen (Pääbo et al. 1988; Golenberg et al. 1990; Richards et al. 1993: 18; Cano et al. 1994: 2.164). Dies war kein singuläres Phänomen dieses Wissenschaftsbereichs: Forensiker wie der amerikanische Genomforscher Eric Lander, einer der Protagonisten des Human Genome Project, propagierten in den 1980er Jahren DNA generell als „ultimate identifier" und "truth machine“ (Lander 1992: 192).

DNA wurde - und wird - über die Fächergrenzen hinweg und sowohl in der deutsch- als auch englischsprachigen Forschungsliteratur als Speichermedium und Archiv bezeichnet, in dem Wissen lagere, das man mit technischer Hilfe auslesen könne. Organismen oder Moleküle schienen, so suggerierten die häufigen Metaphern der Spur, des Wegs oder der Tür, direkt in die Vergangenheit zu führen, ohne den Umweg über Sachkultur und Schriftquellen. ${ }^{22}$ Hier drohe, so die anfängliche Vorstellung, kein Einschlag für Subjektivität, könne im eigentlichen Sinne „wissenschaftlich“ gearbeitet werden, weil molekulare Überreste die unwiderrufliche Basis (evolutions-) historischen Wissens bildeten. Auch von genetischen Zeitreisen war die Rede (Pääbo \& Wilson 1991: 45; Alt 2009: 285; revidiert Pääbo et al. 2004: 670).

Anfangs handelte es sich mehr um euphorische Zukunftsentwürfe und Impulse für die Heuristik als um konkrete wissenschaftliche Forschungsdesigns, denn viele denkbare Anwendungen waren technisch noch unmöglich. Man hatte interessante Effekte im Labor beobachtet, konnte die meisten aber nicht reproduzieren und diskutierte deshalb mehr Ideen, als Routinen zu entwickeln. Manches allerdings ließ sich gut etablieren, so etwa 1989 die durch eine Kooperation der Biochemikern Erika Hagelberg mit dem Forensiker Alec John Jeffreys und anderen entwickelte Extraktion alter DNA aus Knochen (Hagelberg et al. 1989: 485). Hingegen mussten Verfahren für die molekulare Geschlechtsansprache oder die Bestimmung genetischer Verwandtschaft in langwieriger Kleinarbeit gebildet und validiert werden.

Nicht nur die Fachcommunities elektrisierte die Aussicht auf alte DNA. In Science und Nature wie auch in den Massenmedien überstürzten sich eu- 
phorische Meldungen. Der neue Zugang zu alter DNA beflügelte die Phantasie. Sie wecke die Hoffnung der Öffentlichkeit, die Rätsel der Menschheit zu lösen, beobachteten die amerikanische Anthropologin und Wissenschaftsjournalistin Tabitha M. Powledge und der Archäologe Mark Rose (1996: 38).

In technischer Hinsicht beschleunigt wurde das Unterfangen durch die Polymerase Chain Reaction (PCR), einem Verfahren, das um 1990 zur Amplifikation der DNA-Fragmente zur Verfügung stand und die Arbeit auch mit kleinen, schlecht erhaltenen Proben ermöglichte. Populationsgenetische Untersuchungen wurden so erst realisierbar. Da die PCR die Grenzen des Möglichen aufzuheben schien, waren die Reaktionen enthusiastisch zumindest bis nach einigen Jahren ihre methodischen Fallstricke auffielen: Da die PCR so sensitiv ist, besteht ein sehr hohes Risiko, dass bei der Amplifikation kontaminierter Proben Artefakte entstehen (Hagelberg et al. 1989: 485; Pääbo et al. 1989: 9711-9712). Zunächst war die PCR aber einer der wesentlichen technologischen Auslöser des Hype-Zyklus'.

Sensationsmeldungen suggerierten anfangs Anwendbarkeit, die es noch nicht gab. ForscherInnen und Labors aus diversen Fachrichtungen, die sich bisher nicht mit der molekularen Ebene befasst hatten und technisch sowie personell nicht auf die Arbeit mit degradierter DNA vorbereitet waren, sprangen schnell mit auf. So wuchs das Forschungsfeld rasch und Netzwerke entstanden. Im Sommer 1991 kam die Community zu ihrer ersten internationalen Tagung Ancient DNA. The Recovery and Analysis of DNA Sequences from Archaeological Material and Museum Specimens in Nottingham zusammen. Ein Newsletter wurde ins Leben gerufen und der erste Tagungsband erschien. BiologInnen, ForensikerInnen, ZoologInnen, BiochemikerInnen und MolekularbiologInnen und AnthropologInnen, teils mit archäologischer Teilqualifikation, stellten dort ihre Experimente vor. Diese ",first generation' scholars" sollten einen Sachstandsbericht geben, bevor sich, wie man erwartete, das Feld ausdifferenzierte: „before the diversity of disciplines and scientific questions separates workers too much from central issues and themes“ (Herrmann \& Hummel 1994: v).

Laborwissenschaftliche Anteile und alte Moleküle wurden zunehmend in eine Modernisierungserzählung eingehängt. Diese erhielt auch ein Rettungsnarrativ, das die Archäologie betraf. Aus der Sicht des ehemaligen Mainzer Anthropologen Kurt W. Alt, eines Protagonisten der deutschen Molekularen Anthropologie und Initiators zahlreicher überfachlicher Kooperationen, war vor allem die Ur- und Frühgeschichte in den 1990ern auf die molekularen Verfahren und die Biowissenschaften angewiesen, da sie aus eigener Kraft keine innovative Forschung mehr hervorbrachte (Alt 2009: 292). Auf diese und ähnliche Weise wurde dem anderen Fach Erkenntnisfähigkeit abgesprochen, um diskursiv den Modernisierungseffekt 
der neuen Quellen und Methoden zu betonen. Doch waren die Erkenntnisgewinne für die Archäologie zunächst gering.

Zudem kämpften die meisten Anwendungen und Verfahren mit erheblichen Kinderkrankheiten, die aber noch nicht einmal diagnostizierbar waren. Svante Pääbo beschreibt aus der Retrospektive die Frustration, zu wissen, dass, aber nicht warum, ein Verfahren nicht funktionierte. Seit 1989 an der Ludwig-Maximilians-Universität in München, investierte er außergewöhnlich viel Zeit und Ressourcen in die Methodenforschung und ließ sein Team akribisch die eigene Arbeit und die Experimente der Konkurrenten überprüfen (Pääbo 2014: 53-55, 61, 71).

Andere trieben die neuen Techniken und Methoden im „race for the oldest“ (Jones 2001: 9) an ihre Grenzen. Es winkte ein hoher Gewinn an wissenschaftlichem Kapital. Noch gab es keinen nennenswerten Forschungstand, auf den die Labore sich hätten beziehen müssen oder können. Ausgehend von den je eigenen Erkenntnis- und fachpolitischen Interessen, technischen und finanziellen Ressourcen und Karrierestrategien entschieden die Interessierten relativ autonom, welche Fragen sie angehen mochten. Eine Vielzahl solcher Auswahlentscheidungen beeinflusste die weiteren Produktionsbedingungen des wissenschaftlichen aDNA-Wissens. Viele erkannten noch nicht, dass die aDNA-Forschung erhebliche methodische, epistemologische und ökonomische Risiken bereithielt. Einige der „neat tricks“ (Stoneking 1995: 1260) erwiesen sich als Irrtümer oder kontaminationsbedingte Artefakte und endeten im Desaster mit karriereschädigender Wirkung. Die kollegiale Kritik traf dann, auch aus Konkurrenzgesichtspunkten, besonders die Studien, die zunächst große Wellen geschlagen hatten. In Science und Nature wurden vehemente Kontroversen ausgetragen, so zum Beispiel über die Authentizität der angeblichen Chloroplasten-DNA eines Millionen Jahre alten Magnolienblattes und diverse Extraktionen aus Bernsteineinschlüssen. ${ }^{23}$ Besonders heftig geriet die Debatte um eine 1994 veröffentliche angebliche Saurier-Sequenz (Woodward et al. 1994). Die Daten erwiesen sich als kontaminationsbedingte Artefakte. $^{24}$

Solche Fehler avancierten zu prominenten Themen in den Publikationen der Community, die nun mehr und mehr auf die „pitfalls“ ihrer Aktivitäten aufmerksam wurde (Hagelberg 1994: 196, 202). Immer häufiger wurden im Lauf der 1990er Jahre die Authentizitätsfrage gestellt und theoretische Überlegungen unternommen, ob die publizierten Daten überhaupt phylogenetischen Sinn ergaben (Austin et al. 1997: 473; Lalueza-Fox 2003: 168; Pääbo \& Wilson 1991: 46).

Als klar wurde, auf wie vielen Wegen exogene DNA in die Proben gelangen und was sie dort anrichten konnte, wurde Kontamination als Hauptproblem der aDNA-Forschung fixiert (Hagelberg 1994: 196; Handt et al. 
1994: 528; Schmidt et al. 1995: 424-431). Gelangen exogene Moleküle in Proben oder Amplifikate, sind die späteren Sequenzen nicht authentisch. Diese Art der Verunreinigung stört den technischen Ablauf nicht, eher im Gegenteil: Exogene DNA, die oft in besserem molekularen Zustand ist als endogene DNA, wird von der PCR bevorzugt amplifiziert. So entstehen Sequenzdaten, die sehr "schön“ und in technischer Sicht "richtig“ aussehen können, aber nicht authentisch sind. Die Forschungshypothese wird dann mit Daten bearbeitet, die zugleich technisch richtig und falsch sind. Besonders gravierend ist dies, wenn menschliche oder bakterielle DNA untersucht wird, da sich authentische Sequenzen im Nachhinein sehr schwer von Verunreinigungen unterscheiden lassen (Richards et al. 1995: 291; Gigli et al. 2009: 2677; Malmström et al. 2007: 998). So sehr sich die aDNA-Forschung verzweige und spezialisiere, meinte rückblickend die Anthropologin Susanne Hummel, eine Göttinger aDNA-Forscherin der ersten Stunde, sei und bleibe das gemeinsame Thema, das alle verbinde, diese Authentizitätsproblematik (Hummel 2015: 765). Die um die Mitte der 2000 Jahre etablierten NGS-Verfahren haben dem Authentifizierungsproblem lediglich ein anderes Gesicht verliehen: Hochdurchsatzsequenzierer produzieren Millionen von DNA-Sequenzen. Sind einzelne Kontaminationen dabei, fällt das angesichts der riesigen Menge statistisch nicht ins Gewicht, es sei denn, gerade diese werden herausgegriffen und als authentisch deklariert, um eine Hypothese zu belegen (Experteninterview Krause \& Haak 2016).

Zunächst erfüllte die Technologie also nicht die an sie gestellten Erwartungen oder ließ sich nicht so problemlos wie erhofft implementieren. Misserfolge und Karriereeinbrüche wurden im Lauf der 1990er Jahre bekannt und die mediale Berichterstattung ging zurück. Nach Rückschlägen durchhalten konnten Labors mit guten Ressourcen und motivierten Leitungsfiguren. Selbst Svante Pääbo erinnert sich aber daran, nicht mehr daran geglaubt zu haben, dass es gelingen würde, Studien zu menschlicher DNA auch nur annähernd zu authentifizieren (Pääbo 2014: 71). Zeitweise forderte er wie einzelne andere Forscher auch, die Arbeit mit menschlicher DNA ganz aufzugeben. Einige Labors wichen auf Studien zur Phylogenie und Evolution von Pflanzen und (ausgestorbenen) Tieren aus, weil diese als einfacher zu authentifizieren galten (Hagelberg et al. 1994; Höss et al. 1994; Greenwood et al. 1999). Diese Ausweichforschungen haben über die Jahre einen eigenen Erkenntniswert entwickelt und stark zur Methodenentwicklung beigetragen. ${ }^{25}$

Einzelne Arbeitsgruppen setzten primär auf Methodenarbeit und suchten nach Wegen, Kontaminationen zu vermeiden, zu identifizieren oder $\mathrm{zu}$ entfernen. Diverse Kontrollinstrumente entstanden auf diese Weise, und das Wissen über die Charakteristika degradierter DNA und die Bedeutung typischer DNA-Schäden wuchs. Langfristig fiel zum Beispiel auf, dass sich 
die typischen Schadensmuster zur Authentifizierung nutzen ließen (Krause et al. 2010). Nicht verstandene taphonomische und genetische Zusammenhänge, Nichtwissen und Handeln unter den Bedingungen von Ungewissheit und Uneindeutigkeit entwickelten sich zu Kernthemen des Feldes.

Reinheitsstandards, Regelwerke und Sicherheitsregimes sollten Qualitätsstandards für die Arbeit mit degradierter DNA schaffen und helfen, Routinen zu entwickeln, die dann die Ergebnisse vergleichbarer machten. Orientierungs- und Rezeptwissen in Form ausgefeilter Arbeitsanweisungen und „Kochbücher“ sollte die Unsicherheit der Projekte reduzieren. Um das Kontaminationsproblem in den Griff zu bekommen, setzte die aDNACommunity, traditionell molekularbiologisch denkend, auf Kontrolltechnologien bzw. ein kontrollorientiertes Problemmanagement. ${ }^{26}$ Molekularbiologie, Biochemie und Mikrobiologie bearbeiten, vereinfacht gesagt, Probleme und Fehler, indem sie am Experimentsaufbau und Untersuchungsdesign feilen oder nach technischen Fehlern suchen (Wehling 2015: 40-42; Expertinneninterview Grupe 2013). Irrtum, Unsicherheit oder verstörende Daten werden vorrangig einem falschen Untersuchungsaufbau oder Methodenfehlern angelastet.

Unter den aus diesem Grund formulierten Authentifizierungsprotokollen nimmt ein von den Evolutionsbiologen Henrik N. Poinar und Alan Cooper in Science publizierter Kriterienkatalog Ancient DNA: Do It Right or Not at All die wichtigste Stellung ein (Cooper \& Poinar 2000: 1140). Seit seinem Erscheinen im Jahr 2000 wurde er vielfach modifiziert, erweitert und aktualisiert. Solche Maßnahmenkataloge erschienen zunächst in einschlägigen Journals, dann in Hand- und Lehrbüchern sowie in Publikationen, von denen zu erwarten war, dass (Feld-)ArchäologInnen und AnthropologInnen, die für Ausgrabung und Lagerung des Materials verantwortlich waren, sie rezipierten.

Die Kontroll- und Sicherheitsstrategien haben die Qualität der aDNAStudien im Lauf der Jahre verbessert (Krause et al. 2010: 235; Gilbert et al. 2006: 157; Kolman \& Tuross 2000: 18-19). Da sie aber das Authentizitätsproblem nicht lösen konnten, hat ein Großteil der aDNA-ForscherInnen dieses zum Normalfall erklärt und gefordert, das Kontaminationsrisiko in die Interpretationen explizit mit einzubeziehen und dies auch so zu kommunizieren (Yang \& Watt 2005: 331-332; Serre et al. 2004: 0314; Kirsanow \& Burger 2012: 12).

Im Zusammenhang damit wurde der gänzliche Verzicht auf bestimmte Forschungsgegenstände mit erkenntnistheoretischen Argumenten zunehmend abgelehnt (Burger 2006: 55 mit Verweis auf Haak et al. 2005; Hagelberg et al. 2015). Seit der Mitte der 2000er Jahren wandten sich auch wieder mehr Teams Studien an menschlicher und Mikroorganismen-DNA zu (Haak et al. 2015; Allentoft et al. 2015; Bos et al. 2012). Statt Verzicht 
zu üben oder sich nur auf Kontroll- und Sicherheitstechnologien zu verlassen, wurde außerdem zunehmend ein kognitiver Zugang zum Problem gefordert. KritikerInnen argumentierten, dass die Kataloge mit Authentifizierungsmaßnahmen mehr Risiken bargen als vermieden, da sie falsche Sicherheit vermittelten und bei manchen Laboren den Eindruck erweckten, sie seien aus der Verantwortung entlassen, zu prüfen, ob ihre Ergebnisse auch Sinn machten. ${ }^{27}$

Man könne nie beweisen, sondern höchstens in Wahrscheinlichkeiten plausibel machen, wie authentisch Daten seien, lautete ein weiteres Argument (Willerslev \& Cooper 2005: 11). Kritische Evaluationen stellten ohnehin in Frage, wie strikt die Kataloge von den Laboren eingehalten wurden (Ingham \& Roberts 2008: 608; Willerslev \& Cooper 2005: 5; Taylor et al. 2010: 748). Die unabhängige Reproduktion eines Experiments in einem zweiten Labor, ein für die Laborwissenschaften besonders wichtiges Qualitätskriterium, wurde zwar als für die aDNA-Forschung höchst notwendig erachtet, scheiterte in der Praxis aber oft daran, dass nicht genug Probenmaterial für eine Reproduktion vorhanden war. Zudem drohten beim Transport weitere Verunreinigungen. „Alte“ Kontaminationen der Probe ließen sich dadurch auch nicht ausschließen oder leichter aufdecken (z. B. Malmström et al. 2007: 998; Wilbur et al. 2009: 1995). Das Kontrollinstrument war auch schwer mit einem wesentlichen Charakteristikum der Quelle, deren begrenzter Verfügbarkeit, vereinbar. Daran wird deutlich, dass DNA-Quellen sich manchen laborwissenschaftlichen Praktiken verweigern.

Als Komplementärstrategie zu den Kontrollprotokollen wurden Selbstkritik und stärkere theoretische Fundierung der Studien vorgeschlagen. Das bedeute gerade nicht, es sich einfach zu machen, meinte ein englisches Team 2008, denn damit gehe die Beweislast vom Authentifizierungskatalog auf jeden einzelnen Forscher über, „it places the onus for authentication on the researcher rather than on a set of externally-agreed criteria, it does provide a framework within which archaeological research can progress" (Chilvers et al. 2008: 2713). Fehlertolerante Modellierungen wurden als Weg implementiert, mit dem Kontaminationsproblem auf statistische Weise umzugehen (Axelsson et al. 2008: 2186). Insgesamt nahm der Stellenwert probabilistischer Verfahren in den 2000er Jahren zu.

Erkennbar wurden in den 2000er Jahren Anzeichen einer Wissenschaftskultur, in der Fehler, Risiken und Nichtwissen zu einem gewissen Grad akzeptiert, Komplexität und Kontingenz hingenommen und die theoretischen Grundlagen der Methoden und Techniken überdacht werden, und dies auch, zumindest feldintern, kommuniziert wird.

Entgegen der Anfangshoffnungen zeigte sich, dass es neben prinzipiell lösbaren Problemen auch nicht lösbare gab und die Quelle DNA grund- 
sätzliche Aussagegrenzen besaß bzw. einige gewünschte Forschungsdesigns mit alter DNA kaum möglich waren. Erlebt wurde dies teils als SichEmpor-Irren und als schrittweise Arbeit gegen das Noch-Nicht-Wissen, teils aber auch bewusst als Aufdecken des grundsätzlich Nichtwissbaren oder Nichtmachbaren. Feldintern signalisierten die aDNA-ForscherInnen, dass sie von sich nicht mehr ganz große Würfe oder nicht anzweifelbares, eindeutiges Wissen erwarteten. Im Alltag vermischten sich zudem die Instrumente einer kontrollorientierten und einer komplexitätsorientierten Nichtwissenskultur (Böschen et al. 2008; Wehling 2015). Das überrascht nicht, handelt es sich doch um ein Feld, in dem sich Wissenschafts- und damit Nichtwissenskulturen der Laborwissenschaften Molekularbiologie und Biochemie auf der einen, und denen der Evolutionsforschung, Anthropologie und Archäologie auf der anderen Seite treffen. Gerade in der Evolutionsforschung und Genetik lassen sich viele Fragen grundsätzlich nicht experimentell, sondern nur theoretisch angehen. Vergangene evolutionäre Prozesse können nicht einfach unter Laborbedingungen hergestellt oder wiederholt werden.

Ab Anfang der 2000er Jahre ließen die fokussierten Methodenarbeiten und theoretischen Reflexionen allmählich Technik und Verfahren reifen, einen Regelbetrieb entstehen und die Selbsteinschätzungen realistischer werden. Auf diesem Slope of Enlightenment generierten die ForscherInnen belastbares Methoden- und Quellenwissen, um beurteilen zu können, welches konkrete Potential aDNA wirklich für die verschiedenen Fächer und ihre Erkenntnisinteressen hatte - und wo ihre epistemischen und methodischen Grenzen lagen (Hagelberg 1994: 202). Um 2010 begann das Feld sein gegenwärtiges „Produktivitätsplateau“ zu erreichen. Dafür stehen zum Beispiel die Sequenzierung des Neandertalergenoms und anderer ausgestorbener Organismen, die genetische Identifikation der DenisovaMenschen ${ }^{28}$ sowie eine zunehmend größer angelegte Populationsgenetik (Rasmussen et al. 2010; Krause et al. 2010; Noonan et al. 2006).

Zweifellos gibt es Gegenbeispiele, doch insgesamt wurde die aDNACommunity selbstkritischer und vorsichtiger. Auch in sprachlicher Hinsicht verschwand, wie Metaphernanalysen zeigen, zunehmend der technizistische Fortschrittsglaube. Immer mehr Beteiligte räumten ein, dass anfangs unerfüllbare Erwartungen an die DNA angeheizt und die Vorstellung propagiert worden waren, über einen direkten Zugriff auf die "wahre" Vergangenheit zu verfügen. ${ }^{29}$ Bescheidenheit lässt sich der Community nicht attestieren, aber sie gab sich zurückhaltender, je mehr das Feld reifte. Sie ist sich auf dem Weg zu ihrer momentanen Produktivität selbst zu ihrer schärfsten und versiertesten Kritikerin geworden. Die hoch kompetitive Struktur des Feldes förderte dies. Die Herausforderung besteht zunehmend darin, das im Dialog zwischen den Fächern und nach außen 
adäquat zu kommunizieren: Medialen Logiken ist geschuldet, dass Aussagen scheinbar eindeutiger werden, Methodenprobleme kleiner erscheinen und Gewissheitsversprechen häufiger vorkommen, wenn aDNA-ForscherInnen in den Breitenmedien zitiert werden.

Tools und Methoden sind inzwischen relativ stabil und Risiken lassen sich besser einschätzen. Das Feld wächst wieder. Es wird als hochproduktiv und rasant empfunden (Experteninterview Krause \& Haak 2016; Grupe et al. 2012: 154; Harbeck 2012: 190; Burger 2013a). Auf technische Innovationen reagiert die Community interessiert, aber umsichtiger, weil sie die Charakteristika von aDNA immer besser versteht (Hagelberg et al. 2015). Wer jetzt mit einem Labor einsteigt, findet eine gute Orientierungsbasis vor. Allerdings herrsche deshalb, so Wolfgang Haak und Johannes Krause vom Jenaer MPI 2016 im Experteninterview, eine gewisse Goldgräberstimmung. Es gehe um viel Geld und Probenmaterial werde angehäuft in der Erwartung neuer Technologien, die dann neue Anwendungen ermöglichen könnten (Experteninterview Krause \& Haak 2016; auch Callaway 2014).

\section{Die Quelle aDNA in der überfachlichen Debatte}

Je intensiver der Austausch zwischen den beteiligten Fächern der Naturund Geisteswissenschaften im Lauf der 2000er Jahre geriet, desto deutlicher wurden die Grenzen der Quelle DNA erkennbar. Die Archäologie ist nicht mehr nur Probenlieferantin, sondern Partnerin mit eigenen Erkenntnisinteressen in konkreten, auch größeren Forschungsprojekten. ArchäologInnen geben aber auch nicht nur molekulargenetische Expertisen bei einer Hilfswissenschaft in Auftrag, wie das zeitweise von Seiten der Anthropologie befürchtet wurde, sondern haben selbst zumindest zum Teil auch Projekte initiiert, die Erkenntnisgewinne auf allen Seiten versprechen (Soren 2003; Gärtner et al. 2014; Wahl et al. 2014).

In einer Reihe gemeinsamer Fachveranstaltungen der 2010er Jahre wurden einerseits Foren für Bedenken und kollegiale Kritik geschaffen, andererseits sollte wechselseitig Wissen vermittelt werden, um die Validität naturwissenschaftlicher Kompetenzen für historische Fragestellungen offen diskutieren zu können. ${ }^{30}$ ArchäologInnen haben berichtet, sich falsch über die Möglichkeiten und Grenzen der aDNA-Verfahren informiert zu fühlen, während NaturwissenschaftlerInnen klagten, die PartnerInnen wüssten oft gar nicht, was sie mit aDNA-Analysen erreichen könnten, sondern wollten nur schauen, ob irgendetwas herauskomme, wenn sie solche in Auftrag gäben. Das verschwende Ressourcen und führe bestenfalls zu Nice-to-KnowErgebnissen, die den Forschungsstand keines der beteiligten Fächer wei- 
terbrächten. ArchäologInnen wiederum beobachteten, dass der Mangel an Zeit und Gelegenheit, sich in fremde Methodik und Fachkultur einzuarbeiten in ihrem Fach entweder zu naivem Vertrauen in die aDNA-Verfahren oder zu deren völliger Ablehnung geführt habe. ${ }^{31}$ Einige betrachteten es zum Beispiel als Folge des in der Archäologie „zähe[n] Fortleben[n] eines allein auf ,Fakten' zielenden Positivismus“ (Veit 2010: 14), dass FachkollegInnen genetischen Daten zutrauten, objektive und unhintergehbare Antworten zu liefern - und zwar auf Fragen, die oft gar nicht so genau formuliert worden seien (z. B. Gramsch 2011: 210-211). Das hier beanstandete Denken klang in einem Interview mit Andreas Reinecke an, damals zuständig für die Archäologie außereuropäischer Kulturen beim Deutschen Archäologischen Institut, der zur Zusammenarbeit von Archäologie und Naturwissenschaften im Allgemeinen prognostizierte:

All das wird „gefühlsmäßige Interpretation“ in der Archäologie durch harte Fakten ersetzen und streckenweise zu vollkommen neuen Erkenntnissen führen. [...] Da werden wir ganze Weltbilder einstürzen sehen (Reinecke in Bienert et al. 2009: 42).

Die Konfrontation mit der aDNA-Forschung führte im Lauf der Jahre dazu, dass kritische ArchäologInnen solche archäologieinternen Denkweisen skeptisch wahrnahmen und zur Debatte stellten, welchen Stellenwert naturwissenschaftliche Quellen und Expertise überhaupt in den Archäologien einnehmen sollten. Verknüpft wurde dies mit der Aufforderung, mehr über das Wesen der Archäologien nachzudenken: Sei insbesondere die Ur- und Frühgeschichte historische Kulturwissenschaft oder naturwissenschaftliche Archäologie? ${ }^{32}$ Reflexivität wuchs durch den äußeren Anlass, sich und sein Wissenschaftsverständnis, die eigene Fachkultur, die eigenen Begrifflichkeiten und Praktiken in überfachlichen Kooperationsprojekten und auf gemeinsamen Veranstaltungen erklären zu müssen. Um das zu erreichen, bemühten sich die Beteiligten, das Eigene, vermeintlich Bekannte, zu überprüfen und aus der Distanz zu betrachten.

Die Schwierigkeit, die unterschiedlichen Qualitätskriterien wissenschaftlicher Arbeit überfachlich zueinander in Bezug zu setzen, wird zum Beispiel an der Repräsentativitätsdebatte erkennbar: Weil sie oft auf kleinen Samples beruhten, erschienen populationsgenetische Szenarien etwa der Neandertaler- oder Neolithisierungsforschung vielen ArchäologInnen - aber auch GenetikerInnen - als nicht belast- bzw. generalisierbar. ${ }^{33}$ Die formenkundlichen Arbeiten der Ur- und Frühgeschichte und auch die morphologischen Gutachten der Anthropologie basieren demgegenüber oft auf Hunderten von Exemplaren. Unter welchen Bedingungen auch mit kleinen Samples valide Ergebnisse zu erreichen sind, muss immer wieder am Einzelfall verhandelt werden, denn die Verfügbarkeit von Funden und 
deren Zustand, de facto also die Quellenlage, setzt Grenzen. Für viele Zeitstufen und archäologische Kulturen ist es nicht möglich, große Samples für die molekulargenetische Analyse und Populationsgenetik zu bilden.

Vereinbarkeitsprobleme dieser Art wurden nicht nur als Quellenproblem, sondern sogar vorrangig auch als Effekt des Aufeinandertreffens sehr unterschiedlicher Wissenschaftskulturen oder dessen, was man dafür hielt, gedeutet. Das Bild der Two Cultures nach Charles Percy Snow tauchte im aDNA-Kontext immer wieder auf (z. B. Gramsch 2011: 209; Henke 2010a: 173-174). Die Unterschiedlichkeit der Wissenschaftskulturen wurde auch verantwortlich gemacht für Alltagshindernisse und Missverständnisse, schwer vereinbare Publikationsregimes sowie divergierende Belohnungssysteme und Karrierelogiken der einzelnen Fächer (z. B. Samida \& Eggert 2012: 12; Meier \& Tillessen 2011: 36).

Hinter dem, was als sprachliches Missverständnis oder Übersetzungsproblem erlebt wurde (Pusch \& Scholz 1999: 373; Expertinneninterview Grupe 2013; Wagner 2002: 101), steckten hingegen oft divergierende Denkstile und kulturelle Unterbauten (Schurz 1993: 58). Verhandelt wurde darüber, was wissenschaftlich sagbar ist und was nicht. Dies galt besonders für die Frage, ob und wie genetische Daten, wie etwa die Veränderung bestimmter Allelfrequenzen, in geografischer oder kultureller Hinsicht interpretiert werden können und dürfen.

Grundsätzlich lässt sich alte DNA als Quelle nutzen, um die genetische Diversität innerhalb einer Gruppe und Beziehungen zwischen Gruppen sowie deren demografische Strukturen und die Populationsdynamiken der Vergangenheit zu untersuchen. Vor allem GenetikerInnen hatten aber von Beginn auch überlegt, ob es eine Ko-Evolution von Genen, Sprachen und Kulturen gegeben haben könnte und ob sich auch diese untersuchen ließe. Genetische Daten waren geographisch gedeutet worden (z. B. Ammerman \& Cavalli-Sforza 1984). Dies war keine rein genetische Angelegenheit mehr, sondern der Versuch, genetische, archäologische und linguistische Quellen und Konzepte zu kombinieren.

ArchäologInnen rieten demgegenüber vehement davon ab, kultur-, sozial- und geschichtswissenschaftliche Begrifflichkeiten wie Mobilität oder Migration genetisch zu erklären. Sie warnten vor zu einfachen Szenarien und verwiesen darauf, dass solche Begriffe das Ergebnis langer fachinterner Verhandlungen seien. ${ }^{34}$ Dies galt besonders für die ethnische Interpretation und die Vorstellung, dass sich materielle Kulturen, Räume und biologische und soziale Gruppen und Ethnien entsprechen, von der sich die urund frühgeschichtliche Archäologie erst seit den 2000er Jahren in einer aufreibenden Kontroverse entfernt hatte. In dieser Debatte, die als „Minenfeld“ bezeichnet wurde (Müller-Scheeßel \& Burmeister 2006: 14), war es in Deutschland sogar um die Fachidentität gegangen, denn Befürworter 
der ethnischen Interpretation hatten in ihr jene Sinnstiftung erkannt, die die Archäologie leisten müsse, um ein historisch arbeitendes Fach zu sein (Bierbrauer 2004: 47, 49; kritisch Burmeister 2013: 237-240). Durchgesetzt hatten sich ihre Gegner (Brather 2013). Der erkämpfte Stand sollte nun nach außen verteidigt werden. Eine archäologische Kultur sollte nur als Verbreitung von Sachguttypen verstanden werden und nicht als soziale oder biologische Gruppe von Menschen. Nicht nur ArchäologInnen, sondern auch GenetikerInnen und AnthropologInnen bezweifelten zunehmend und sehr grundsätzlich, dass genetische Gruppen und Entwicklungen mit geografischen Räumen, kulturellen oder sozialen Prozessen zusammen zu bringen seien, und betonten, dass genetische Gruppenbegriffe eine ganz andere diachrone Bedeutung als soziale oder kulturelle Gruppenbegriffe hätten. ${ }^{35}$ Das verstünden manche Paläogenetiker noch nicht, so der Mainzer Anthropologe Joachim Burger, und bedienten sich in einem „Kaufhaus der Kulturen“ (Burger 2013b). Mit der aDNA werde „Schindluder“ getrieben, erklärte der Prähistoriker Eggert, wenn soziokulturelle Phänomene als kausale Erklärung für molekulargenetische Daten herangezogen würden (Experteninterview Eggert 2013; ausführlich Eggert 2012: 35-37).

Verknüpft war dies mit dem Forschungsproblem, ob Kulturwandel, das heißt die Veränderung der Verbreitung eines Artefakttyps, zwingend mit einer substantiellen Bevölkerungsbewegung einhergehen musste (Burmeister 2000: 539-540). Von älteren Migrationskonzepten, die einen solchen Zusammenhang unter anderem für die Neolithisierung propagiert hatten, löste sich die Ur- und Frühgeschichte in den 1990er und 2000er Jahren (Scarre 2002: 404; Gronenborn 1999: 124). Stattdessen wurde Kulturwandel zunehmend mit der Mobilität von Ideen und Konzepten und maximal kleiner kultureller Eliten erklärt (Burmeister 2000: 539-540). Für das Neolithikum beispielsweise fanden sich keine belastbaren archäologischen Quellen, die eine substantielle und weitreichende Wanderung einer größeren Gruppe von Menschen nahegelegt hätten, in deren Folge es zu dem sehr wohl archäologisch feststellbaren Wandel der Wirtschafts- und Lebensweisen gekommen war (Zvelebil 2002: 382). Vielmehr wurde die Neolithisierung zunehmend als mosaikartiges Gebilde unterschiedlichster Prozesse aufgefasst, zu denen sowohl Kulturaustausch als auch größere und kleinere Kolonisationsvorgänge und temporäre Mobilität vorkamen (Zvelebil 2002: 382; Thomas 2006: 53).

Just in dieser Situation konfrontierten PaläogenetikerInnen die Ur- und Frühgeschichte jedoch mit modernen und alten DNA-Daten, die als Beleg für eine signifikante Bevölkerungsbewegung interpretiert werden konnten (Chiki et al. 2002: 11009-11013; Barbujani \& Dupanloup 2002: 424, 430; Bramanti et al. 2009: 138). Wachsende Samples und technische Innovationen der zweiten Hälfte der 2000er Jahre bis hin zu den genomweiten 
Untersuchungen an Menschen, domestizierten Tieren und Pflanzen ergaben dann ein Szenario, wonach eine Bevölkerungsgruppe, die allerdings doch klein gewesen sein kann, prozedurales Wissen, Tiere und Techniken für die produzierende Lebensweise aus dem Vorderen Orient mit nach Europa. Ihr Beitrag zur dortigen genetischen Struktur wurde je nach Region unterschiedlich hoch angesetzt. Betont wurden zunehmend die Komplexität und Prozesshaftigkeit dieses Vorgangs. ${ }^{36}$ Einiges davon passte, wie es der Prähistoriker Jens Lüning gelassen ausdrückte, zu den archäologischen Befunden, anderes nicht. Divergierende Ansichten gebe es vor allem über die Intensität der Bevölkerungsbewegung (Lüning 2014: 43).

Skepsis lösten populationsgenetische Migrationsszenarien und die erneute Begründung kulturellen Wandels mit Bevölkerungsverschiebungen nun nicht nur in den Archäologien, sondern zum Beispiel auch beim Mainzer Anthropologen Joachim Burger aus, der diese neue Deutungskonjunktur kritisch wahrnahm. Er erklärte in einem Vortrag vor Archäologen, auffällig sei doch „seit es Isotopenanalysen und aDNA gibt, migriert alles“ (Burger 2013a). Die Urgeschichtlerin Daniela Hofmann hingegen erklärte das Unbehagen der ArchäologInnen damit, dass diese nun mit einem aus ihrer Sicht veralteten Szenario konfrontiert wurden:

It seems that as a discipline, we are being asked to go back to an explanatory paradigm we have long left behind and to equate an archaeological culture with a new population. This throwback is shaking our ambition to be a sophisticated, humanities-aligned discipline, and archaeologists rightly refuse to give up the theoretical insights of many decades of research (Hofmann 2015: 457).

Insgesamt erlaubt die Kombination der vielen archäologischen, genetischen, zoologischen, morphologischen, isotopengeochemischen, botanischen und linguistischen Einzelergebnisse der 2000er und 2010er Jahre aus der Sicht vieler ForscherInnen unterschiedlicher Fächer durchaus eine Art Minimalkompromiss: Bei der Neolithisierung handelte es sich offenbar um einen langwierigen und variantenreichen Wandlungsprozess, der um 12.000 BP im Nahen Osten begann, in Südosteuropa um 8.500 BP feststellbar war, regional höchst unterschiedlich verlief und wenig universelle Trends aufwies (Burger \& Thomas 2011: 378; Brotherton et al. 2013: 6). Die Befunde aller beteiligten Fächer wurden zunehmend komplexer. Die alte Forschungsfrage war nicht, wie anfangs von der aDNA-Forschung erwartet, auf molekularer Ebene eindeutig und einfach entschieden worden. Im Gegenteil sind seit dem Zugang zu den DNA-Quellen nicht nur die Antworten, sondern auch die Fragen zur Neolithisierung selbst komplizierter geworden. Dasselbe Phänomen trat in der Neandertalerforschung und bei Studien auf, die der Besiedelung der Amerikas nachgehen. Auf ihrer Su- 
che nach einfachen Antworten und simplen Narrativen zeigten die aDNAProjekte letztlich vielmehr Komplexität und Kontingenz auf. ${ }^{37}$

\section{Fazit}

Über den Bezug zum gemeinsamen Wissensgegenstand (alte) DNA traten ForscherInnen aus den Natur- und Geisteswissenschaften seit den 1980er Jahren miteinander in Kontakt. Sie schufen sich eine molekulare Erkenntnisebene, definierten DNA zur Quelle für historische Fragestellungen und machten sie damit für das Geschichtsbewusstsein relevant. Angehörige aus einer Vielzahl von Fächern, Forschungsrichtungen und Wissenschaftskulturen haben im Lauf der 1990er Jahre ein heterogenes Forschungsfeld aufgebaut. In international orientierten Fachnetzwerken wird an evolutionshistorischen, populationsgenetischen und archäologischen Fragestellungen gearbeitet. Die aDNA-Forschung durchlief einen Hype-Zyklus, der durch technologische Auslöser wie insbesondere die Polymerase Chain Reaction, die die Amplifikation der DNA-Fragmente erleichterte, in der zweiten Hälfte der 1980er Jahre in Gang gesetzt worden war. Erste spektakuläre Experimente stießen auf großes fachliches und mediales Interesse. Die epistemologischen und fachpolitischen Erwartungen waren hoch und große Reputation winkte. Zahlreiche Labore und Forschungseinheiten versuchten Fragestellungen und Anwendungsgebiete zu besetzen, die meist seit Längerem in der Evolutionsforschung, Genetik, Anthropologie und Archäologie verfolgt worden waren und dort jeweils ihre eigene Fachgeschichte hatten. Die neue Quelle sollte neue Erkenntnisse ermöglichen und viele der großen „alten“ Fragen dieser Fächer endgültig entscheiden. Doch erwies sich degradierte DNA als hoch problematisches Material. Experimente scheiterten und die Technologie litt an diversen Kinderkrankheiten. Auf den „Gipfel der überzogenen Erwartungen“ um 1990 folgte Desillusionierung. Das Interesse der Medien ließ nach, Karrieren litten und ein Teil der Arbeitsgruppen verließ das Feld wieder. Andere investierten Zeit und Forschungsgelder in die systematische Suche nach Fehlern und Fehlerquellen und den Grenzen der Technologie. Technische und methodische Routinen entstanden in akribischer Arbeit und die Charakteristika der Quelle wurden klarer. Verunreinigungen und die Schwierigkeit, aDNA-Sequenzen zu authentifizieren, wurden als Kernprobleme ausgemacht. Die PCR erwies sich als Ermöglichungstechnologie und Problemverstärkerin zugleich. Das Eingeständnis, dass prinzipielle Probleme der Quelle technisch nicht beherrschbar und die Authentifizierungsschwierigkeiten sogar charakteristisch für die Arbeit mit degradierter DNA waren, mündete in mehreren 
Coping-Strategien. Einzelne Forschungsgegenstände wurden zeitweise zugunsten sicherer Ausweichforschungen aufgegeben und diverse Kontrollund Sicherheitsprotokolle und Kriterienkataloge wurden erstellt. Eine andere Strategie waren Versuche, das Problem theoretisch bzw. statistisch anzugehen. Auch deshalb kamen Mathematik, Statistik und Bioinformatik zunehmende Bedeutung zu.

Die aDNA-Community hat ihre anfänglichen Versprechen auf die technische Beherrschbarkeit der molekularen Welt weitgehend relativiert und Kontingenz infolge der diversen Rückschläge und des vertieften Wissens über die Charakteristika alter Moleküle schrittweise akzeptiert. Mit ihren Bekenntnissen zu Ambivalenz und Ungewissheit löst sie sich schrittweise von der Vorstellung exakter wissenschaftlicher Wahrheit und vom Eindeutigkeitsversprechen der ersten Moderne. Routinen und Standards wissenschaftlichen Arbeiten wurden entwickelt und im überfachlichen Miteinander verhandelt. Dies waren Schritte des Feldes auf seinem „Pfad der Erleuchtung“. Der ausgeprägte Konkurrenzgedanke förderte die feldinterne Kontrolle. Reflexivitätsgewinne bei allen beteiligten Wissenschaften gingen aber auch aus Alltagskonflikten und gezielt eröffneten Diskussionen der Fächer miteinander einher, denn sie führten zu Selbstbefragungen und der Prüfung der je eigenen Qualitätskriterien und Fachverständnisse.

Aus der Sicht der Beteiligten hat die aDNA-Forschung am Ende der 2000er Jahre ein hohes Produktivitätsniveau erreicht. Doch ist kein Stillstand eingetreten. Im Gegenteil - die Arbeitseinheiten sind laufend auf der Suche nach neuen Experimenten oder neuen Techniken, die für die Analyse alter DNA adaptiert werden könnten.

Die Anforderungen, die die Quelle DNA an Quellenkritik und Interpretation stellt, unterscheiden sich eher in technischer als in prinzipieller Hinsicht von denen anderer Quellen. Selektivität, Perspektivität und Standortgebundenheit sind typische Charakteristika aller historischen Quellen. Erheblichen technischen und kognitiven Aufwand bringt aufgrund des ubiquitären Kontaminationsproblems die Echtheitsprüfung mit sich. Next Generation Sequencing hat das Authentizitätsproblem zwar verändert, es aber nicht aufgehoben.

Über eine mögliche Hierarchie oder Konkurrenz von Quellen wurde immer wieder diskutiert. Doch hängt der Wert einer Quelle von der Fragestellung ab, die WissenschaftlerInnen formulieren. Die beteiligten Angehörigen der Genetik, prähistorischen Archäologie und Anthropologie sowie die PaläoepidemiologInnen und PopulationsgenetikerInnen verfolgen oft sehr unterschiedliche Fragestellungen zu einer gemeinsamen Thematik bzw. interessieren sich für unterschiedliche Aspekte derselben. Deshalb können molekulare Quellen nicht per se mehr oder gewissere, sondern schlichtweg andere Informationen liefern als beispielsweise Sachgut. 
Die Herausforderung besteht darin, die jeweiligen Daten und Erkenntnisse miteinander in Verbindung zu bringen und Teilergebnisse auf ihre Kohärenz mit den Wissensbeständen anderer Fächer zu prüfen. Die Schwierigkeit, Quellen, Daten und Deutungen im überfachlichen Miteinander in Verbindung zu setzen, offenbarten die Diskussionen darüber, ob es möglich und zulässig ist, genetische Einheiten mit geografischen Räumen in Verbindung zu bringen und sie soziokulturell zu interpretieren. An der Neolithisierungsfrage wurde zudem deutlich, dass die neue, zusätzliche Quelle gerade nicht eine einfache, haltbare Lösung brachte, sondern das Bild der Vergangenheit und in der Folge auch neue Fragestellungen sehr viel komplexer machte als angenommen.

Für HistorikerInnen ist jetzt ein guter Zeitpunkt, sich mit diesem Feld auseinanderzusetzen (Samida \& Feuchter 2016). Das beginnt bei gemeinsamen Konferenzen und der gegenseitigen Rezeption der Forschungsliteratur. Der nächste Schritt sind kooperative Testprojekte, wie das vom Mediävisten Patrick J. Geary am Institute for Advanced Studies in Princeton initiierte Unterfangen zur Migrationsgeschichte der sogenannten Völkerwanderungszeit (Geary 2013; Geary \& Veeramah 2016). Er will nicht nur beobachten, was sich in der Genetik tut, sondern aus der Perspektive und mit dem Instrumentarium der Mediävistik selbst genetic history mit betreiben. In Nature ließ er sich zitieren: „If historians do not get involved and engage with this technology seriously, we're going to see more and more studies that are done by geneticists with very little input from historians, or from frankly second-rate historians" ([o.V.] 2016: 438).

Kritiker sehen darin einen gefährlichen Einbruch der Genetik in die Mediävistik (Keupp 2014). Gearys Befürworter hingegen verstehen das Projekt als einen im Zeitalter der Biologie, Age of Biology, erforderlichen Türöffner. Man komme, so der Mediävist Jörg Feuchter, an der aDNAForschung nicht vorbei und müsse für Dialog und Übersetzung sorgen (Feuchter 2014; auch McCormick 2008: 86-89, 95-97; ähnlich Brather 2016: 37). So werde sich zeigen, ob und wie Genetische Geschichte in der Zusammenarbeit mit Molekular- und Evolutionsgenetik, Biochemie und Anthropologie funktionieren kann.

Im Zeitalter der Biologie erscheint es selbstverständlich, dass auch die Geschichtswissenschaft in eine Art "critical friendship" mit denjenigen eintritt, die Geschichtsforschung auf der Basis biologischer Quellen betreiben (Adeney Thomas 2014: 1603; Gordin 2014: 1621; Rummel in Summer 2016). Der Auftrag der Geisteswissenschaften besteht darin, die Naturwissenschaften kritisch nach ihren Erkenntnisgrenzen und Qualitätskriterien zu befragen und zugleich selbstkritisch auch das Eigene zu überprüfen.

Es gibt Gemeinsamkeiten zu entdecken: die Charakteristika der Quellen, die Wege zum Wissen, das Interesse am Leben in der Vergangenheit, 
den hohen narrativen Anteil der jeweiligen Arbeit. Reibungslos kann dies nicht verlaufen, da erstens immer auch Fachpolitiken, historische gewachsene Auffassungen von Fachkompetenzen und Machtverhältnisse berührt werden, und zweitens Konflikte ohnehin konstitutiv für wissenschaftliche Erkenntnisprozesse sind.

\section{Anmerkungen}

1 Wortmeldungen von Jan Keupp und Johannes Paulmann im Rahmen des Kolloquiums und der Podiumsdiskussion sowie des Plenums in: TU Darmstadt (2016). Siehe auch Keupp (2014) sowie die Leserkommentare. Auch Gordin (2014: 1621, 1625, 1629); Pohl (2016, S. 2 f.).

2 Johannes Krause etwa in a.r.t.e.s. (2016) und Summer (2016); Wolfgang Haak in TU Darmstadt (2016); Kurt W. Alt, Mark Jobling und Brigitte Pakendorf in Zentrum für Zeithistorische Forschung (2015).

3 http://www.spiegel.de/suche/index.html?suchbegriff=svante+p\%E4\%E4bo\& offsets $=57 \&$ pageNumber=2, (27.2.2016); Neanderthal Man ist der Titel seiner Autobiografie: Pääbo (2014).

4 Vgl. etwa Pollard (2011: 637); referiert bei Expertinneninterview Samida (2013); Horsburgh (2015: 141).

$5 \quad$ Als Beispiel dafür das Interview mit Andreas Reinecke in Bienert et al. (2009: 42). Das Zitat im Titel bei Kristiansen (2014: 11).

6 Sozialität und Geschichtlichkeit würden in den Biohistories nicht kulturell, sondern biologisch begründet, so Sommer (2012: 378).

7 Gordin (2014: 1629).

8 Aus Platzgründen sind im Folgenden nur beispielhafte Belege möglich.

9 Vgl. Horsburgh (2015: 144); Experteninterview Krause \& Haak (2016).

10 Richards et al. (1993: 22-23); Mulligan (2006: 366); Hummel (2003: 23); MatisooSmith \& Horsburgh (2012: 13).

11 Dabei macht man sich zunutze, dass jedes Individuum auf den homologen Chromosomen von Mutter und Vater je ein Allel, d. h. eine der möglichen Varianten einer Sequenz an einem bestimmten Ort der DNA (locus), besitzt. Untersucht man mehrere und bestimmte Kombination von Loci, lassen sich Abstammungen in beiden Linien bestimmen.

12 Das Human Genome Project kam zu dem Ergebnis, dass nicht-codierende Sequenzen 95 Prozent des menschlichen nuklearen Genoms ausmachen. Proteine sind die Bausteine des Organismus. Sie bestehen aus Ketten von Aminosäuren. Die DNA-Sequenz in den Genen, d. h. den codierenden Bestandteilen der DNA, gibt die Abfolge der Aminosäuren im Protein vor, die wiederum die Funktion des Proteins bestimmt.

13 Vgl. exemplarisch den Nachweis des FOXP2-Gens bei Neandertalern. FOXP2 ist für die Plastizität der neuronalen Schaltkreise im Gehirn zuständig ist und wird mit Sprechfähigkeit bzw. seine Mutation mit spezifischen Sprechstörungen in Verbindung gebracht. Vgl. Krause et al. (2007: 1908); Green et al. (2010: 710).

14 Vgl. Expertinneninterview Hummel (2013); Experteninterview Krause \& Haak (2016); Mulligan (2006: 366).

15 In den USA werden Anthropology und Archaeology meist zusammen zur Four-FieldsAnthropology gezählt, wo sie als integrierte Partnerinnen wahrgenommen werden. 
16 Als Projektbeispiele Haak et al. (2010); Flindt (2010); Gill \& Hagelberg (2004); Muhl et al. (2010); Owsley et al. (2006); Weichhold et al. (1998). Aus den Medien Eggebrecht (2015); Krohn (2008); Schulz (2015); Vowinkel (2008); Seewald (2010); [o.V.] (2007, 2008a, 2008b).

17 Gemeint sind Unternehmen wie 23andme, deCODEme, ancestry.com, iGENIA und insbesondere die Firma Oxford Ancestors des britischen Humangenetikers Brian Sykes.

18 Hagelberg (2002: 77); Bandelt et al. (2008: 1246-1247); Pääbo in Herden (2010); Experteninterview Burger (2013); Expertinneninterview Grupe (2013).

19 Vgl. Fenn \& Raskino (2008: 8-15). Ich danke Ulrich Wengenroth für seine Hinweise zum Hype-Zyklus.

20 Collar et al. (2015: 3).

21 Vgl. etwa Hummel et al. (1995: 61). Zur „Molekularisierung“ der biologischen Fächer und zur Leitfunktion der Molekularbiologie Morange (1998: 179-183).

22 Die Metaphernanalyse beruht auf einem Sample von ca. 900 deutsch- und englischsprachigen Titeln.

23 Vgl. beispielsweise Golenberg et al. (1990); Poinar et al. (1993); Cano et al. (1994); DeSalle et al. (1992); Höss et al. (1994: 333); kritisch zu Golenberg etwa Sidow et al. (1991: 429, 432 f.); Lindahl (1993: 712 f.).

24 Vgl. Zischler et al. (1995: 1192-1193); mit anderer Beweisführung etwa Hedges \& Schweitzer (1995: 1191) sowie weitere in derselben Ausgabe von Science. Dazu Gibbons (1994: 1159).

25 Thomas et al. (1989: 467); Cooper et al. (1992); Hagelberg et al. (1994); Höss et al. (1994); Krajewski et al. (1997).

26 Wehling (2015: 40) auf der Basis der Laborstudien von Karin Knorr-Cetina. Zur Systematik Böschen et al. (2008).

27 Gilbert et al. (2005: 541 f.); Mulligan (2006: 368); Hagelberg (2012: 106); Fulton (2012: 4).

28 Es handelt sich um die erste Menschenart, die nicht zuerst morphologisch, sondern molekular angesprochen wurde.

29 Herrmann (2011: 474); Bandelt et al. (2002: 104); Expertinneninterview Hummel (2013); Expertinneninterview Grupe (2013); Experteninterview Burger (2013).

30 Vgl. etwa Meller \& Alt (2010); Claßen \& Schön (2014: 7); Samida \& Feuchter (2016).

$31 \mathrm{Zu}$ den genannten Beobachtungen und Befürchtungen aus archäologischer Sichtweise unter anderem Experteninterview Gärtner (2016); Samida \& Eggert (2013: 105); Gramsch (2011: 210); für die Anthropologie Expertinneninterview Hummel (2013); Grupe (2012: 185); Harbeck (2012: 190); Burger (2013a).

32 Vgl. Samida \& Eggert (2012: 15-19); Gramsch (2011: 214); Leney (2006: 48); anders Kristiansen (2014: 20-22, 27).

33 Vgl. Barbujani \& Dupanloup (2002: 429); Lalueza-Fox (2003: 170); Grupe et al. (2012: 156); Uthmeier (2013); Hofmann (2015: 458); Horsburgh (2015: 144).

34 Burmeister (2000: 540-541); Gramsch (2005: 189 f.); Brather (2009: 49); Siegmund (2014: 55-57); Experteninterview Meier (2013).

35 Vgl. u. a. Gilbert et al. (2005: 543); Burger \& Thomas (2011: 373); Haeseler et al. (1996: 136); Goldstein \& Chikhi (2002: 144 f.); Expertinneninterview Hummel (2013).

36 Pinhasi et al. (2012: 496); Skoglund et al. (2012: 467-469); Fu et al. (2012: e32473: 5); Lazaridis et al. (2014: 412).

37 Prognostiziert schon von Jones (2001: 235). Auch Matisoo-Smith \& Horsburgh (2012: 125). 


\section{Literatur}

[o.V.] 2007: Verwandte aus der Bronzezeit. Menschen aus dem Südharz stammen von Höhlenmenschen ab. Berliner Morgenpost, 6.7.2007 (181): 11.

[o.V.] 2008a: Im Tode für immer vereint. Lausitzer Rundschau, 6.12.2008.

[o.V.] 2008b: Gentest enthüllt ältesten Beleg für Kleinfamilie. Leipziger-Volkszeitung, 18.11.2008: 5 .

[o.V.] 2014: AHR Roundtable. History Meets Biology. Introduction. American Historical Review 119 (5): 1492-1499.

[o.V.] 2016. Source Material. Nature (533): 437-438.

a.r.t.e.s. Graduate School for the Humanities Cologne, Universität zu Köln 2016. Konferenzprogramm: Urkunde - DNA - Fingerabdruck: Wer kann wie Geschichte erforschen? 17.6.2016. URL: http://hsozukult.geschichte.hu-berlin.de/termine/id=31062 (1.1.2016).

Adeney Thomas, Julia 2014. History and Biology in the Anthropocene: Problems of Scale, Problems of Value. American Historical Review 119 (5): 1587-1607.

Allentoft, Morten E., Martin Sikora, Karl-Goran Sjogren und Simon Rasmussen et al. 2015. Population Genomics of Bronze Age Eurasia. Nature (522): 167-172.

Alt, Kurt W. 2009. Prähistorische Anthropologie im 21. Jahrhundert. Methoden und Anwendungen. In: Orsolya Heinrich-Tamaska, Niklot Krohn und Sebastian Ristow (Hg.). Dunkle Jahrhunderte in Mitteleuropa? Tagungsbeiträge der Arbeitsgemeinschaft Spätantike und Frühmittelalter: 1. Rituale und Moden (Xanten, 8.6.2006) und 2. Möglichkeiten und Probleme archäologisch-naturwissenschaftlicher Zusammenarbeit (Schleswig, 9.-10.10.2007). Hamburg: Kovač: 273-292.

Ammerman, Albert J. und Luigi Luca Cavalli-Sforza 1984. The Neolithic Transition and the Genetics of Populations in Europe. Princeton NJ: Princeton University Press.

Austin, Jeremy. J., Andrew J. Ross, Andrew B. Smith und Richard A. Fortey et al. 1997. Problems of Reproducibility - Does Geologically Ancient DNA Survive in Amber-preserved Insects? Proceedings of the Royal Society B (264): 467-474.

Axelsson, E., Eske Willerslev, M. Thomas P. Gilbert und Rasmus Nielsen 2008. The Effect of Ancient DNA Damage on Inferences of Demographic Histories. Molecular Biology and Evolution (25): 2181-2187.

Bandelt, Hans-Jürgen, Vincent Macaulay und Martin B. Richards 2002. What Molecules Can't Tell Us About the Spread of Languages and the Neolithic. In: Colin Renfrew und Peter S. Bellwood (Hg.). Examining the Farming/Language Dispersal Hypothesis. Cambridge: McDonald Institute for Archaeological Research: 99-107.

Bandelt, Jürgen, Yong-Gang Yao, Martin B. Richards und Antonio Salas 2008. The Brave New Era of Human Genetic Testing. BioEssays (30):1246-1251.

Barbujani, Guido und Isabelle Dupanloup 2002. DNA Variation in Europe: Estimating the Demographic Impact of Neolithic Dispersals. In: Colin Renfrew und Peter S. Bellwood (Hg.). Examining the Farming/Language Dispersal Hypothesis. Cambridge: McDonald Institute for Archaeological Research: 421-433.

Bienert, Hans-Dieter, Rüdiger Krause, Dirk Krausse und Harald Meller et al. 2009. AiDJubiläum. Neun Experten und ihre Sicht auf die Archäologie. 25 Jahre AiD - Rückschau und Ausblick. Archäologie in Deutschland. 38-43.

Bierbrauer, Volker 2004. Zur ethnischen Interpretation in der frühgeschichtlichen Archäologie. In: Walter Pohl (Hg.). Die Suche nach den Ursprüngen. Von der Bedeutung des frühen Mittelalters. Wien: Verl. der Österreichischen Akad. der Wiss.: 45-84.

Bos, Kirsten I., Philip Stevens, Kay Nieselt und Hendrik N. Poinar et al. 2012. Yersinia pestis: New Evidence for an Old Infection. PLoS ONE (7): e49803.

Böschen, Stefan, Karen Kastenhofer, Ina Rust und Jens Soentgen et al. 2008. Entscheidungen unter Bedingungen pluraler Nichtwissenskulturen. In: Renate Mayntz, Friedhelm Neidhardt, Peter Weingart und Ulrich Wengenroth (Hg.). Wissensproduktion und Wissenstransfer: Wissen im Spannungsfeld von Wissenschaft, Politik und Öffentlichkeit. Bielefeld: transcript: 197-219. 
Bramanti, Barbara, Mark G. Thomas, Wolfgang Haak und Martina Unterländer et al. 2009. Genetic Discontinuity between Local Hunter-gatherers and Central Europe's First Farmers. Science (326): 137-140.

Brather, Sebastian 2009. Ethnische Interpretationen in der europäischen Archäologie. Wissenschaftliche und politische Relevanz. In: Judith Schachtmann, Michael Strobel und Thomas Widera (Hg.). Politik und Wissenschaft in der prähistorischen Archäologie. Perspektiven aus Sachsen, Böhmen und Schlesien. Göttingen: V\&R: 31-51.

Brather, Sebastian 2013. „In stammeskundlichen Fragen erschien es angebracht, möglichste Zurückhaltung zu üben." Ethnische Interpretationen und frühgeschichtliche Archäologie. In: Gabriele Rasbach (Hg.). Westgermanische Bodenfunde: Akten des Kolloquiums anlässlich des 100. Geburtstages von Rafael von Uslar am 5./6.12. 2008 in Frankfurt a.M. Bonn: Habelt: 53-61.

Brather, Sebastian 2016. New Questions Instead of Old Answers: Archaeological Expectations of aDNA Analysis. Medieval Worlds (4): 22-41.

Brotherton, Paul, Wolfgang Haak, Jennifer Templeton und Guido Brandt et al. 2013. Neolithic Mitochondrial Haplogroup H Genomes and the Genetic Origins of Europeans. Nature Communications (4), 1764: 1-11.

Brown, Terence A. und Keri A. Brown 2011. Biomolecular Archaeology. An Introduction. Chichester: Wiley.

Burger, Joachim 2006. Zwischen Kontamination und Authentizität - Der Nachweis menschlicher DNA aus archäologischen Skeletten. In: Carsten Niemitz (Hg.). Brennpunkte und Perspektiven der aktuellen Anthropologie. Focuses and perspectives of modern physical anthropology. Berlin: BGAEU: 53-59.

Burger, Joachim 2013. Vortrag: Populationsgenetik des Neolithikums. Deutsche Gesellschaft für Ur- und Frühgeschichte: Archäologie und Paläogenetik, Erlangen 10.5.2013, Transkript der Verfasserin.

Burger, Joachim 2013a. Vortragstranskript: Populationsgenetik des Neolithikums. Tagung: Archäologie und Paläogenetik. Deutsche Gesellschaft für Ur- und Frühgeschichte. Erlangen, 10.5.2013.

Burger, Joachim 2013b: Diskussionsbeitrag zum Vortrag von Frank Siegmund: Kulturen, Völker und Identitätsgruppen - Eine Übersicht über die archäologische Diskussion. Transkript. Deutsche Gesellschaft für Ur- und Frühgeschichte. Erlangen, 10.5.2013.

Burger, Joachim und Mark G. Thomas 2011. The Palaeopopulationgenetics of Humans, Cattle and Dairying in Neolithic Europe. In: Ron Pinhasi und Jay T. Stock (Hg.): Human Bioarchaeology of the Transition to Agriculture, Hoboken NJ: Wiley: 370-384.

Burmeister, Stefan 2000. Archaeology and Migration. Approaches to an Archaeological Proof of Migration. Current Anthropology (41): 539-567.

Burmeister, Stefan 2013. Migration und Ethnizität: Zur Konzeptionalisierung von Mobilität und Identität. In: Manfred K. H. Eggert, Ulrich Veit und Melanie Augstein (Hg.). Theorie in der Archäologie. Zur jüngeren Diskussion in Deutschland. Münster: Waxmann: 229-268.

Callaway, Ewen 2014. The Neanderthal in the Family. Nature (507): 414-416.

Cann, Rebecca L., Mark Stoneking und Allan C. Wilson 1987. Mitochondrial DNA and Human Evolution. Nature (325): 31-36.

Cano, Raul J., Monika K. Borucki, Mary Higby-Schweitzer und Hendrik N. Poinar et al. 1994. Bacillus DNA in Fossil Bees: An Ancient Symbiosis? Applied and Environmental Microbiology (60): 2164-2167.

Chiki, Lounès, Richard A. Nichols, Guido Barbujani und Mark A. Beaumont 2002. Y Genetic Data Support the Neolithic Demic Diffusion Model, in: Proceedings of the National Academy of Sciences of the United States of America (99): 11008-11013.

Chilvers, Elizabeth R., Abigail S. Bouwman, Keri A. Brown und Robert G. Arnott et al. 2008. Ancient DNA in Human Bones from Neolithic and Bronze Age Sites in Greece and Crete. Journal of Archaeological Science (35): 2707-2714.

Claßen, Erich und Werner Schön 2014. Die DGUF-Tagung 2013: „Archäologie und Paläogenetik“ - eine Einführung. Archäologische Informationen (37): 7-8.

Collar, Anna, Fiona Coward, Toms Brughmans und Barbara J. Mills et al. 2015. Networks in Archaeology. Phenomena, Abstraction, Representation. Journal of Archaeological Method and Theory (22): 1-32. 
Cooper, Alan, C. Mourer-Chauvire, G.K. Chambers und Arndt von Haeseler et al. 1992. Independent Origins of the New Zealand Moas and Kiwis. Proceedings of the National Academy of Sciences of the United States of America (89): 8741-8744.

Cooper, Alan und Hendrik N. Poinar 2000. Ancient DNA: Do It Right or Not at All. Science (289): 1139.

DeSalle, Rob, J. Gatesy, W. Wheeler und D. Grimaldi 1992. DNA Sequences from a Fossil Termite in Oligo-Miocene Amber and their Phylogenetic Implications. Science (257): 1933-1936.

Eggebrecht, Harald 2015. Das Massaker von Eulau, in: SZ.de, 24.7.2015. URL: http://www. sueddeutsche.de/stil/das-geheimnis-das-massaker-von-eulau-1.2577817 (30.11.2016).

Eggert, Manfred K.H. 2005. Archäologie als Historische Kulturwissenschaft: ein Projektbericht. Archäologisches Nachrichtenblatt (10): 220-233.

Eggert, Manfred K. H. 2012. Prähistorische Archäologie. Konzepte und Methoden. 4., überarb. Aufl. Tübingen: UTB.

Eggert, Manfred K.H. 2016. Geneticizing Bantu: Historical Insight or Historical Trilemma? Medieval Worlds (4): 79-90.

Eggert, Manfred K.H. 2013. Bantu und Indogermanen: Zur vergleichenden Anatomie eines sprach- und kulturgeschichtlichen Phänomens. Saeculum (62): 1-62.

Experteninterview mit Joachim Burger, Erlangen 20.5.2013.

Experteninterview mit Johannes Krause und Wolfgang Haak, Jena 24.3.2016.

Experteninterview mit Manfred K. H. Eggert, Berlin 25.5.2013.

Experteninterview mit Thomas Meier, Berlin 24.5.2013.

Experteninterview mit Tobias Gärtner, München/Jena 7.7.2016.

Expertinneninterview mit Gisela Grupe, München 20.3.2013.

Expertinneninterview mit Susanne Hummel, Göttingen 22.3.2013.

Expertinneninterview mit Stefanie Samida, Potsdam 20.5.2013.

Fenn, Jackie und Mark Raskino 2008. Mastering the Hype Cycle. How to Choose the Right Innovation at the Right Time. Boston, MA: Harvard Business Press.

Feuchter, Jörg 2014. Die DNA der Geschichte, in: FAZ, 5.11.2014.

Flindt, Stefan 2010. Die Menschen aus der Lichtensteinhöhle. Größter DNA-Pool der Bronzezeit. In: Matthias Knaut und Roland Schwab (Hg.). Archäologie im 21. Jahrhundert. Innovative Methoden - bahnbrechende Ergebnisse. Stuttgart: Theiss: 22-29.

Fu, Qiaomei, Pavao Rudan, Svante Pääbo und Johannes Krause et al. 2012. Complete Mitochondrial Genomes Reveal Neolithic Expansion into Europe. PLOS ONE (7): e32473.

Fulton, Tara L. 2012. Setting Up an Ancient DNA Laboratory. In: Beth Shapiro und Michael Hofreiter (Hg.) Ancient DNA. Methods and Protocols. New York: Humana Press: 1-11.

García-Sancho, Miguel 2012. Biology, Computing, and the History of Molecular Sequencing. From Proteins to DNA, 1945-2000. Basingstoke: Palgrave Macmillan.

Gärtner, Tobias, Brigitte Haas-Gebhard, Michaela Harbeck und Franziska Immler et al. 2014. Frühmittelalterliche Frauen in Waffen? Divergenzen zwischen der archäologischen und anthropologischen Geschlechtsansprache. Bayerische Vorgeschichtsblätter (79): 219-240.

Geary, Patrick J. 2013. Using Genetic Data to Revolutionalize Unterstanding of Migration History. URL: https://www.ias.edu/ideas/2013/Geary-history-genetics (20.2.2016).

Geary, Patrick J. und Krishna Veeramah 2016. Mapping European Population Movement through Genomic Research. Medieval Worlds (4): 65-78.

Gibbons, Ann 1994: Possible Dino DNA Find is Greeted with Skepticism. Science (266): 1159.

Gigli, Elena, Morten Rasmussen, Sergi Civit und Antonio Rosas 2009. An Improved PCR Method for Endogenous DNA Retrieval in Contaminated Neandertal Samples Based on the Use of Blocking Primers. Journal of Archaeological Science (36): 2676-2679.

Gilbert, M. Thomas P., Anders J. Hansen, Eske Willerslev und Gordon Turner-Walker et al. 2006. Insights into the Processes behind the Contamination of Degraded Human Teeth and Bone Samples with Exogenous Sources of DNA. International Journal of Osteoarchaeology (16): 156-164.

Gilbert, M. Thomas P., Hans-Jürgen Bandelt, Michael Hofreiter und Ian Barnes 2005. Assessing Ancient DNA Studies. Trends in Ecology E Evolution (20): 541-544.

Gill, Peter und Erika Hagelberg 2004. Ongoing Controversy over Romanov Remains: Letter. Science (306): 408-409. 
Goldstein, David B. und Lounès Chikhi 2002. Human Migrations and Population Structure: What we Know and Why it Matters. Annual Review of Genomics and Human Genetics (3): 129-152.

Golenberg, Edward M., D.E. Giannasi, Margaret Clegg und C.J. Smiley et al. 1990. Chloroplast DNA Sequence from a Miocene Magnolia Species. Nature (344): 656-658.

Gordin, Michael 2014: Comment: Evidence and the Instability of Biology. American Historical Review (119): 1621-1629.

Gramsch, Alexander 2005. Archäologie und post-nationale Identitätssuche. Archäologisches Nachrichtenblatt (10): 185-193.

Gramsch, Alexander 2011. Jenseits der „Zwei Kulturen“: Transfer und Transformation von Daten und Fragen zwischen Disziplinen. In: Thomas Meier und Petra Tillessen (Hg.). Über die Grenzen und zwischen den Disziplinen. Fächerübergreifende Zusammenarbeit im Forschungsfeld historischer Mensch-Umwelt-Beziehungen. Budapest: Archaeolingua: 209-217.

Green, Richard E., Johannes Krause, Adrian W. Briggs und Tomislav Maricic et al. 2010. A Draft Sequence of the Neandertal Genome. Science (328): 710-722.

Greenwood, Alex D., Cristian Capelli, Göran Possnert und Svante Pääbo 1999. Nuclear DNA Sequences from Late Pleistocene Megafauna. Molecular Biology and Evolution (16): 1466-1473.

Gronenborn, Detlef 1999. A Variation on a Basic Theme: The Transition to Farming in Southern Central Europe. Journal of World Prehistory (13): 123-264.

Grupe, Gisela 2012. Stable Isotope Analysis in Bioarchaeological Research - Difficult questions, Easy answers? In: Dies., George McGlynn und Joris Peters (Hg.). Current Discoveries from Outside and Within. Field Explorations and Critical Comments from the Lab. Rahden: Leidorf. 175-188.

Grupe, Gisela, Kerrin Christiansen, Inge Schröder und Ursula Wittwer-Backofen et al. 2012. Anthropologie. Einführendes Lehrbuch. 2. Aufl. Berlin: Springer.

Haak, Wolfgang, Peter Forster, Barbara Bramanti und Shuichi Matsumura et al. 2005. Ancient DNA from the First European Farmers in 7500-Year-Old Neolithic Sites. Science (310): 1016-1018.

Haak, Wolfgang, Guido Brandt, Christian Meyer und Hylke de Jong et al. 2010. Die schnurkeramischen Familiengräber von Eulau - ein außergewöhnlicher Fund und seine interdisziplinäre Bewertung. In: Harald Meller und Kurt W. Alt (Hg.). Anthropologie, Isotopie und DNA - biografische Annäherung an namenlose vorgeschichtliche Skelette? 2. Mitteldeutscher Archäologentag vom 8.-10.10.2009 in Halle. Halle: Landesamt für Denkmalpflege und Archäologie Sachsen-Anhalt: 53-61.

Haak, Wolfgang, Iosif Lazaridis, Nick Patterson und Nadin Rohland et al. 2015. Massive Migration from the Steppe was a Source for Indo-European Languages in Europe. Nature (522): 207-211.

Haeseler, Arndt von, Antti Sajantila und Svante Pääbo 1996. The Genetical Archaeology of the Human Genome, in: Nature Genetics (14): 135-140.

Hagelberg, Erika 1994. Mitochondrial DNA from Ancient Bones. In: Bernd Herrmann und Susanne Hummel (Hg.). Ancient DNA. Recovery and Analysis of Genetic Material from Paleontological, Archaeological, Museum, Medical, and Forensic Specimens. New York: Springer: 195-204.

Hagelberg, Erika 2002. Book Review: The Seven Daughters of Eve. Heredity (89): 77.

Hagelberg, Erika 2012. Analysis of DNA from Bone: Benefits versus Losses. In: Hallvard Fossheim/Norwegian National Research Ethics Committee (Hg.). More than Just Bones. Ethics and Research on Human Remains, o.O.: o.V.: 95-112.

Hagelberg, Erika, Brian Sykes und Robert E.M. Hedges 1989. Ancient Bone DNA Amplified. Nature (342): 485.

Hagelberg, Erika, Mark G. Thomas, Charles E. Cook und Andrej V. Sher et al. 1994. DNA from Ancient Mammoth Bones. Nature (370): 333-334.

Hagelberg, Erika, Michael Hofreiter und Christine Keyser 2015. Introduction. Ancient DNA: the First Three Decades. Philosophical Transactions of the Royal Society B (370): 20130371.

Handt, Oliva, Matthias Höss, Matthias Krings und Svante Pääbo et al. 1994. Ancient DNA: Methodological Challenges. Experientia (50): 524-529. 
Harbeck, Michaela 2012. Molecular Genetic Analysis of Archaeological Skeletal Remains all that Glitters Is not Gold. In: Gisela Grupe, George McGlynn und Joris Peters (Hg.). Current Discoveries From Outside and Within. Field Explorations and Critical Comments from the Lab. Rahden: Leidorf: 189-206.

Hedges, S. Blair und Mary Schweitzer 1995. Detecting Dinosaur DNA: Technical Comment. Science (268): 1191-1192.

Henke, Winfried 2010a. Wissenschaftshistorische Betrachtung der Beziehung zwischen Paläoanthropologie und Älterer Urgeschichte. Mitteilungen der Gesellschaft für Urgeschichte (19): 173-192.

Henke, Winfried 2010b. Zur narrativen Komponente einer theoriegeleiteten Paläoanthropologie. In: Balz Engler (Hg.). Erzählen in den Wissenschaften. Positionen, Probleme, Perspektiven. Freiburg: Academic Press Fribourg: 83-103.

Herden, Birgit 2010: Ahnensuche im Schmelztiegel. Sz.de, 19.5.2010. URL: http://www. sueddeutsche.de/wissen/erbgut-ahnensuche-im-schmelztiegel-1.913522 (30.11.2016).

Herrmann, Bernd 1997. Perspektiven in der Prähistorischen Archäologie? Anthropologischer Anzeiger (55): 97-100.

Herrmann, Bernd 2011. Innerfachliches und Fächerübergreifendes aus einer anthropologischen Sicht und historische Mensch-Umwelt-Beziehungen. In: Thomas Meier und Petra Tillessen (Hg.). Über die Grenzen und zwischen den Disziplinen. Fächerübergreifende Zusammenarbeit im Forschungsfeld historischer Mensch-Umwelt-Beziehungen. Budapest: Archaeolingua: 471-485.

Herrmann, Bernd und Susanne Hummel 1994. Preface. In: Dies. (Hg.). Ancient DNA. Recovery and Analysis of Genetic Material from Paleontological, Archaeological, Museum, Medical, and Forensic specimens. New York: Springer: v.

Higuchi, Russel, Barbara Bowman, Mary Freiberger und Oliver A. Ryder et al. 1984. DNA Sequences from the Quagga, an Extinct Member of the Horse Family. Nature (312): $282-284$.

Hofmann, Daniela 2015. What Have Genetics Ever Done for Us? The Implications of aDNA Data for Interpreting Identity in Early Neolithic Central Europe. European Journal of Archaeology (18): 454-476.

Hofreiter, Michael 2009. Spurensuche in alter DNA. Molekulare Paläontologie. Biologie in unserer Zeit (39): 176-184.

Horsburgh, K. Ann 2015. Molecular Anthropology: the Judicial Use of Genetic Data in Archaeology. Journal of Archaeological Science (56): 141-145.

Höss, Matthias, Svante Pääbo und N.K. Vereshchagin 1994. Mammoth DNA Sequences. Nature (370): 333.

Hummel, Susanne 2003. Ancient DNA Typing. Methods, Strategies and Applications. Berlin: Springer.

Hummel, Susanne 2015. Ancient DNA. In: Winfried Henke und Ian Tattersall (Hg.). Handbook of Paleoanthropology, 2. Aufl. Berlin: Springer: 763-790.

Hummel, Susanne, Gabriele Nordsiek, Jens Rameckers und Cadja Lassen et al. 1995. aDNA Ein neuer Zugang zu alten Fragen. Zeitschrift für Morphologie und Anthropologie (81): 41-65.

Ingham, Sarah und Charlotte A. Roberts 2008. Using Ancient DNA analysis in Palaeopathology: A Critical Analysis of Published Papers, with Recommendations for Future Work. International Journal of Osteoarchaeology (18): 600-613.

Jones, Martin K. 2001. The Molecule Hunt. Archaeology and the Search for Ancient DNA. London: Allen Lane.

Keupp, Jan 2014. Kein Wunder nirgendwo - die genetische Herausforderung der Geschichte, Mittelalter.hypotheses, 18.11.2014. URL: http://mittelalter.hypotheses.org/4734 (6.1.2016).

Kirsanow, Karola und Joachim Burger 2012. Ancient Human DNA. Annals of Anatomy (194): 121-132.

Knapp, Michael und Michael Hofreiter 2010. Next Generation Sequencing of Ancient DNA: Requirements, Strategies and Perspectives. Genes (1): 227-243.

Kolman, Connie J. und Noreen Tuross 2000. Ancient DNA Analysis of Human Populations. American Journal of Physical Anthropology (111): 5-23. 
Krajewski, C., L. Buckley und M. Westerman 1997. DNA Phylogeny of the Marsupial Wolf Resolved. Proceedings of the Royal Society B (264): 911-917.

Krause, Johannes, Adrian W. Briggs, Martin Kircher und Tomislav Maricic et al. 2010. A Complete mtDNA Genome of an Early Modern Human from Kostenki, Russia. Current Biology (20): 231-236.

Krause, Johannes, Carles Lalueza-Fox, Ludovic Carles und Wolfgang Enard et al. 2007. The Derived FOXP2 Variant of Modern Humans Was Shared with Neandertals. Current Biology (17): 1908-1912.

Kristiansen, Kristian 2014. Towards a New Paradigm? The Third Science Revolution and its Possible Consequences in Archaeology. Current Swedish Archaeology (22): 11-34.

Krohn, Knut 2008. Ein Geniestreich: Bei der Identifizierung des Grabes von Kopernikus halfen Technik, Glück und kriminalistisches Gespür. Der Tagesspiegel, 30.11.2008: 36.

Lalueza-Fox, Carles 2003. Bone Collections are DNA Data Banks. In: Gisela Grupe und Joris Peters (Hg.). Decyphering Ancient Bones. The Research Potential of Bioarchaeological Collections. Rahden: Leidorf: 165-174.

Lander, Eric S. 1992. DNA Fingerprinting: Science, Law, and the Ultimate Identifier. In: Daniel Jo Kevles und Leroy Edward Hood (Hg.). The Code of Codes. Scientific and Social Issues in the Human Genome Project. Cambridge, MA: Harvard University Press: 191-210, 345-346.

Lazaridis, Iosif, Nick Patterson, Alissa Mittnik und Gabriel Renaud et al. 2014. Ancient Human Genomes Suggest Three Ancestral Populations for Present-day Europeans. Nature (513). 409-413.

Leney, Mark D. 2006. Sampling Skeletal Remains for Ancient DNA. A Measure of Success. Historical Archaeology (40): 31-49.

Lindahl, Tomas 1993. Instability and Decay of the Primary Structure of DNA. Nature (362): 709-715.

Lüning, Jens 2014. Einiges passt, anderes nicht: Archäologischer Wissensstand und Ergebnisse der DNA-Anthropologie zum Frühneolithikum. Archäologische Informationen (37): 43-51.

Malmström, Helena, Emma M. Svensson, M. Thomas P. Gilbert, Eske Willerslev, Anders Götherström und Gunilla Holmlund 2007. More on Contamination: The Use of Asymmetric Molecular Behaviour to Identify Authentic Ancient Human DNA. Molecular Biology and Evolution (24): 998-1004.

Mathieson, Iain, Iosif Lazaridis, Nadin Rohland und Swapan Mallick et al. 2015. Genomewide Patterns of Selection in 230 Ancient Eurasians. Nature (528): 499-503.

Matisoo-Smith, Elizabeth A. und K. Ann Horsburgh 2012. DNA for Archaeologists. Walnut Creek, CA: Left Coast Press.

McCormick, Michael 2008. Molecular Middle Ages: Early Medieval Economic History in the Twenty-First Century. In: Jennifer R. Davis und Ders. (Hg.). The Long Morning of Medieval Europe. New Directions in Early Medieval Studies. Aldershot, Ashgate: 83-97.

Meier, Thomas und Petra Tillessen 2011. Von Schlachten, Hoffnungen und Ängsten: Einführende Gedanken zur Interdisziplinarität in der Historischen Umweltforschung. In: Dies. (Hg.). Über die Grenzen und zwischen den Disziplinen. Fächerübergreifende Zusammenarbeit im Forschungsfeld historischer Mensch-Umwelt-Beziehungen. Budapest: Archaeolingua: 19-43.

Meller, Harald und Kurt W. Alt 2010. Vorwort. In: Dies. (Hg.). Anthropologie, Isotopie und DNA - biografische Annäherung an namenlose vorgeschichtliche Skelette? 2. Mitteldeutscher Archäologentag vom 8.-10.10.2009 in Halle. Halle: Landesamt für Denkmalpflege und Archäologie Sachsen-Anhalt: 7-8.

Meuser, Michael und Ulrike Nagel 2009. Das Experteninterview - konzeptionelle Grundlagen und methodische Anlage. In: Susanne Pickel, Gert Pickel, Hans-Joachim Lauth und Detlef Jahn (Hg.). Methoden der vergleichenden Politik- und Sozialwissenschaft. Wiesbaden: VS: 465-479.

Morange, Michel 1998.: A History of Molecular Biology. Cambridge Mass.: Harvard University Press.

MPI für Menschheitsgeschichte Jena 2016a. Programm: Neue Methoden in Archäologie und Geschichtswissenschaften. Workshop für Doktorand/-innen und Postdocs der Archäolo- 
gie und Geschichte, 27.-28.5.2016. URL: http://www.shh.mpg.de/events/4280/141888 (1.8.2016).

MPI für Menschheitsgeschichte Jena 2016b. Institutsprofil. URL: www.shh.mpg.de (16.5. 2016).

Muhl, Arnold, Harald Meller und Klaus Heckenhahn (Hg.) 2010. Tatort Eulau. Ein 4500 Jahre altes Verbrechen wird aufgeklärt. Darmstadt: WBG.

Müller-Scheeßel, Nils und Burmeister, Stefan 2006. Einführung: Die Identifizierung sozialer Gruppen. Die Erkenntnismöglichkeiten der prähistorischen Archäologie auf dem Prüfstand. In: Dies. (Hg.). Soziale Gruppen - kulturelle Grenzen. Die Interpretation sozialer Identitäten in der prähistorischen Archäologie. Münster: Waxmann: 9-38.

Mulligan, Connie J. 2006. Anthropological Applications of Ancient DNA: Problems and Prospects. American Antiquity (71): 459-462.

Natural History Museum of Denmark, Centre for GeoGenetics: Research Groups. URL: http://geogenetics.ku.dk/research_groups/ (11.7.2016).

Noonan, James P., Graham Coop, Sridhar Kudaravalli, Doug Smith, Johannes Krause, Joe Alessi, Feng Chen, Darren Platt, Svante Pääbo, Jonathan K. Pritchard und Edward M. Rubin 2006. Sequencing and Analysis of Neanderthal Genomic DNA. Science (314): 1113-1118.

Orlando, Ludovic, Aurélien Ginolhac, Guojie Zhang, Duane Froese, Anders Albrechtsen, Mathias Stiller, Mikkel Schubert, Enrico Cappellini, Bent Petersen, Ida Moltke, Philip L. F. Johnson, Matteo Fumagalli, Julia T. Vilstrup, Maanasa Raghavan, Thorfinn Korneliussen, Anna-Sapfo Malaspinas, Josef Vogt, Damian Szklarczyk, Christian D. Kelstrup, Jakob Vinther, Andrei Dolocan, Jesper Stenderup, Amhed M. V. Velazquez, James Cahill, Morten Rasmussen, Xiaoli Wang, Jiumeng Min, Grant D. Zazula, Andaine Seguin-Orlando, Cecilie Mortensen, Kim Magnussen, John F. Thompson, Jacobo Weinstock, Kristian Gregersen, Knut H. Røed, Véra Eisenmann, Carl J. Rubin, Donald C. Miller, Douglas F. Antczak, Mads F. Bertelsen, Søren Brunak, Khaled A. S. Al-Rasheid, Oliver Ryder, Leif Andersson, John Mundy, Anders Krogh, M. Thomas P. Gilbert, Kurt Kjær, Thomas Sicheritz-Ponten, Lars Juhl Jensen, Jesper V. Olsen, Michael Hofreiter, Rasmus Nielsen, Beth Shapiro, Jun Wang und Eske Willerslev 2013. Recalibrating Equus Evolution Using the Genome Sequence of an Aarly Middle Pleistocene Horse. Nature (499): 74-78.

Owsley, Douglas W., Brooks B. Ellwood und Terry Melton 2006. Search for the Grave of William Preston Longley, Hanged Texas Gunfighter. Historical Archaeology (40): 50-63.

Pääbo, Svante 1985. Molecular Cloning of Ancient Egyptian Mummy DNA. Nature (314): 644-645.

Pääbo, Svante, Hendrik N. Poinar, David Serre und Viviane Jaenicke-Després et al. 2004. Genetic Analyses from Ancient DNA. Annual Review of Genetics (38): 645-679.

Pääbo, Svante, J.A. Gifford und Allan C. Wilson 1988. Mitochondrial DNA Sequences from a 7000-year Old Brain. Nucleic Acids Research (16): 9775-9787.

Pääbo, Svante, Russel Higuchi und Allan C. Wilson 1989. Ancient DNA and the Polymerase Chain Reaction. The Emerging Field of Molecular Archaeology. Journal of Biological Chemistry (264): 9709-9712.

Pääbo, Svante und Allan C. Wilson 1991. Miocene DNA Sequences - a Dream Come True? Current Biology (1): 45-46.

Pääbo, Svante 2014. Neanderthal Man. In Search of Lost Genomes. New York: Basic Books. Pickrell, Joseph K. und David Reich 2014. Toward a New History and Geography of Human Genes Informed by Ancient DNA. Trends in Genetics (30): 377-389.

Pinhasi, Ron, Mark G. Thomas, Michael Hofreiter, Mathias Currat und Joachim Burger 2012. The Genetic History of Europeans. Trends in Genetics (28): 496-505.

Pluciennik, Mark 1996. Genetics, Archaeology and the Wider World. Antiquity (70): 13-14. Pohl, Walter 2016. Editor's Introduction: The Genetic Challenge to Medieval History and Archaeology. Mediaeval Worlds (4): 2-4.

Poinar, Hendrik N., Raul J. Cano und George O. Poinar 1993. DNA from an Extinct Plant. Nature (363): 677.

Pollard, A. Mark 2011. Isotopes and Impact: A Cautionary Tale. Antiquity (85): 631-638.

Powledge, Tabitha M. und Mark Rose 1996. The Great DNA Hunt. Archaeology (49): 36-44. 
Pusch, Carsten M. und Michael Scholz 1999. Paläogenetik - Methodik und Ziele eines neuen naturwissenschaftlichen Forschungsansatzes in der Archäologie. Fundberichte aus Baden-Württemberg (23): 367-374.

Rasmussen, Morten, Yingrui Li, Stinus Lindgreen und Jakob Skou Pedersen et al. 2010. Ancient Human Genome Sequence of an Extinct Palaeo-Eskimo. Nature (463): 757-762.

Richards, Martin B., Kate Smalley, Brian Sykes und Robert E.M. Hedges 1993. Archaeology and Genetics: Analysing DNA from Skeletal Remains. World Archaeology (25): 18-28.

Richards, Martin B., Brian Sykes und Robert E.M. Brian 1995. Authenticating DNA Extracted from Ancient Skeletal Remains. Journal of Archaeological Science (22): 291-299.

Samida, Stefanie und Feuchter, Jörg 2016. Why Archaeologists, Historians and Geneticists Should Work Together - and How. Medieval Worlds (4): 5-21.

Samida, Stefanie und Manfred K.H. Eggert 2012. Über Interdisziplinarität. Betrachtungen zur Kooperation von Natur- und Kulturwissenschaften in der Archäologie. Hephaistos (29): 9-24.

Samida, Stefanie und Manfred K.H. Eggert 2013. Archäologie als Naturwissenschaft? Eine Streitschrift. Berlin: Vergangenheitsverlag.

Sanger, Frederick 1988. Sequences, Sequences, and Sequences. Annual Review of Biochemistry (57):1-28.

Scarre, Chris 2002. Pioneer Farmers? The Neolithic Transition in Western Europe. In: Colin Renfrew und Peter S. Bellwood 2002 (Hg.). Examining the Farming/Language Dispersal Hypothesis. Cambridge: McDonald Institute for Archaeological Research: 395-407.

Schmidt, Tobias, Susanne Hummel und Bernd Herrmann 1995. Evidence of Contamination in PCR Laboratory Disposables. Naturwissenschaften (82): 423-431.

Schulz, Matthias 2015. König unter Altöl. DER SPIEGEL, 10.1.2015: 124.

Schurz, Robert 1993. Studien zur Möglichkeit von Interdisziplinarität: Die universitären Denkstile. Darmstadt: Meurer.

Seewald, Bethold 2010. Die Mörder kamen vom Harz herunter. DIE WELT, 31.12.2010: 27.

Serre, David, André Langaney, Mario Chech, Maria Teschler-Nicola, Maja Paunovic, Philippe Mennecier, Michael Hofreiter, Göran Possnert und Svante Pääbo 2004. No Evidence of Neandertal mtDNA Contribution to Early Modern Humans. PLoS Biology (2): e57.

Shapiro, Beth, M. Thomas P. Gilbert und Ian Barnes 2008. Using DNA to Investigate the Human Past. In: Holger Schutkowski (Hg.). Between Biology and Culture. Cambridge: Cambridge Univ. Press: 207-242.

Sidow, Arend, Allan C. Wilson und Svante Pääbo 1991. Bacterial DNA in Clarkia Fossils. In: Philosophical Transactions of the Royal Society B (333): 429-433.

Siegmund, Frank 2014. Kulturen, Technokomplexe, Völker und Identitätsgruppen: eine Skizze der archäologischen Diskussion. Archäologische Informationen (37): 53-65.

Skoglund, Pontus, Helena Malmström, Maanasa Raghavan, Jan Storå, Per Hall, Eske Willerslev, M. Thomas P. Gilbert, Anders Götherström und Mattias Jakobsson 2012. Origins and Genetic Legacy of Neolithic Farmers and Hunter-gatherers in Europe. Science (336): 466-469.

Sommer, Marianne 2008. Molecules as Documents of Evolutionary History. Wie Gene Träger der Geschichte des Menschen und der Menschen wurden. Figurationen (9): 109-128.

Sommer, Marianne 2012. Gen und phylogenetisches Gedächtnis. Individuelle und kollektive genetische Geschichten im Netzwerk von Naturwissenschaft, Identitätspolitik und Markt. In: Johannes Friedrich Lehmann (Hg.). Die biologische Vorgeschichte des Menschen. Zu einem Schnittpunkt von Erzählordnung und Wissensformation. Freiburg: Rombach: 377-391.

Soren, David 2003. Can Archaeologists Excavate Evidence of Malaria? World Archaeology (35): 193-209.

Stoneking, Mark 1995. Ancient DNA: How Do You Know when You Have it and What Can You Do with it? American Journal of Human Genetics (17): 1259-1262.

Summer, Michael 2016: Tagungsbericht: Archäologie, Geschichte und Biowissenschaften. Interdisziplinäre Perspektiven, 19.11.-21.11.2015 Freiburg. Institut für Archäologische Wissenschaften, Institut d'histoire romaine Université de Strasbourg, ArcHiMédE Unité Mixte de recherche 7044. URL: http://www.hsozkult.de/conferencereport/id/ tagungsberichte-6363 (1.2.2016). 
Taylor, G. Michael, Simon A. Mays und J.F. Huggett 2010. Ancient DNA (aDNA) Studies of Man and Microbes: General Similarities, Specific Differences. International Journal of Osteoarchaeology (20) 747-751.

Thomas, Julian 2006: Gene-flows and Social Processes: The Potential of Genetics and Archaeology. Documenta Prehistorica (33): 51-59.

Thomas, Richard H., Walter Schaffner, Allan C. Wilson und Svante Pääbo 1989. DNA Phylogeny of the Extinct Marsupial Wolf. Nature (340): 465-467.

TU Darmstadt 2016: Podiumsdiskussion: Geschichte als Naturwissenschaft? Podiumsdiskussion zu Perspektiven biologischer Forschung in der Geschichtswissenschaft. Darmstadt 26.1.2016, Transkript der Verfasserin.

Uthmeier, Thorsten 2013. Vortragstranskript: Individuen, Gruppen und Identität: Zur Identifikation sozialer Einheiten im Paläolithikum. Tagung: Archäologie und Paläogenetik. Deutsche Gesellschaft für Ur- und Frühgeschichte. Erlangen, 10.5.2013.

Veit, Ulrich 2010. Zur Geschichte und Theorie des Erzählens in der Archäologie: eine Problemskizze. Ethnographisch-archäologische Zeitschrift (51): 10-29.

Veit, Ulrich 2011. Über das „Geschichtliche“ in der Archäologie - und über das „Archäologische" in der Geschichtswissenschaft. In: Stefan Burmeister und Nils Müller-Scheeßel (Hg.). Fluchtpunkt Geschichte. Archäologie und Geschichtswissenschaft im Dialog. Münster: Waxmann: 297-310.

Vowinkel, Heike 2008. Die Verwandten aus der Bronzezeit. Welt am Sonntag, 13.7.2008: 13.

Wagner, Günther A. 2002. Archaeometry in Germany: Progress and Deficits. In: Academia Nazionale dei Lincei (Hg.). Archaeometry in Europe in the Third Millennium. Convegno internazionale Roma, 29.-30.3.2001. Roma: Accademia nazionale dei Lincei: 97-108.

Wahl, Joachim, Giovanna Cipollini, Valentina Coia und Michael Francken et al. 2014. Neue Erkenntnisse zur frühmittelalterlichen Separatgrablege von Niederstotzingen, Kreis Heidenheim. Fundberichte aus Baden-Württemberg (34): 341-390.

Waldron, Tony 1991. DNA in Bones. International Journal of Osteoarchaeology (1): 155-156.

Wehling, Peter 2015. Nichtwissenskulturen - Theoretische Konturen eines neuen Konzepts der Wissenschaftsforschung. In: Ders. und Stefan Böschen (Hg.) Nichtwissenskulturen und Nichtwissensdiskurse. Über den Umgang mit Nichtwissen in Wissenschaft und Öffentlichkeit. Baden-Baden: Nomos 2015: 23-66.

Weichhold, G.M., J.E. Bark, W. Korte und Wolfgang Eisenmenger et al. 1998. DNA Analysis in the Case of Kaspar Hauser. International Journal of Legal Medicine (111): 287-291.

Wilbur, Alicia K., Abigail S. Bouwman, Anne C. Stone und Charlotte A. Roberts, Luz Andrea Pfister, Jane E. Buikstra und Terence A. Brown 2009. Deficiencies and Challenges in the Study of Ancient Tuberculosis DNA. Journal of Archaeological Science (36): 1990-1997.

Willerslev, Eske und Alan Cooper 2005. Review Paper: Ancient DNA. Proceedings of the Royal Society B (272): 3-16.

Woodward, Scott R., N.J. Weyand und M. Bunnell 1994. DNA Sequence from Cretaceous Period Bone Fragments. Science (266): 1229-1232.

Yang, Dongya Y. und Kathy Watt 2005. Contamination Controls when Preparing Archaeological Remains for Ancient DNA Analysis. Journal of Archaeological Science (32): 331-336.

Zentrum für Zeithistorische Forschung und Humboldt Universität zu Berlin 2015. Programm: Genetic History: A Challenge to Historical and Archaeological Studies, 1.-2.10. 2015, Potsdam. URL: http://www.genetic-history.com/wissenschaft/programm.htm (20.7.2016).

Zischler, Hans, Matthias Höss, Oliva Handt, Arndt von Haeseler, AC van der Kuyl und Jaap Goudsmit 1995. Detecting Dinosaur DNA: Technical Comment. Science (268): 1192-1193.

Zuckerkandl, Emile und Linus Pauling 1965. Molecules as Documents of Evolutionary History. Journal of Theoretical Biology (8): 357-366.

Zvelebil, Marek 2002. Demography and Dispersal of Early Farming Populations at the Mesolithic-Neolithic Transition: Linguistic and Genetic Implications. In: Colin Renfrew und Peter S. Bellwood (Hg.). Examining the Farming/Language Dispersal Hypothesis. Cambridge: McDonald Institute for Archaeological Research: 379-394. 
Elsbeth Bösl

Professur für Wirtschafts-, Sozial- und Technikgeschichte,

Historisches Seminar

Universität der Bundeswehr München

Werner-Heisenberg-Weg 39

85577 Neubiberg

Deutschland

elsbeth.boesl@unibw.de 